\title{
The International Synchronisation of Business Cycles: the Role of Animal Spirits
}

\author{
Paul De Grauwe ${ }^{1}$ - Yuemei $\mathbf{J i}^{2}$
}

Published online: 12 April 2017

(C) The Author(s) 2017. This article is published with open access at Springerlink.com

\begin{abstract}
Business cycles among industrial countries are highly correlated. We develop a two-country behavioral macroeconomic model where the synchronization of the business cycle is produced endogenously. The main channel of synchronization occurs through a propagation of "animal spirits", i.e. waves of optimism and pessimism that become correlated internationally. We find that this propagation occurs with relatively low levels of trade integration. We do not need a correlation of exogenous shocks to generate synchronization. We also empirically test the main predictions of the model.
\end{abstract}

Keywords Animal spirits · Behavioral macroeconomics · Business cycles

\section{Introduction}

An important empirical feature of the international economy is the high correlation of the business cycles across countries. We show this feature both for the group of Eurozone countries and a group of industrialized countries outside the Eurozone. Table 1 presents the bilateral correlations of the business cycle components of GDP in the Eurozone. The business cycle component is obtained by using a Hodrick-Prescott (HP) filter on GDP data. We apply a similar procedure for the group on industrial countries outside the Eurozone.

It is striking to find how high these correlation coefficients are. This is especially the case within the Eurozone were we find many correlation coefficients of the business cycle components exceeding 0.9 . On average we find that this correlation coefficient is 0.82 , suggesting a very high degree of synchronization of the business cycles within the Eurozone. This is confirmed in Fig. 1 showing the evolution of the business cycle

Paul De Grauwe

p.c.de-grauwe@1se.ac.uk

1 London School of Economics, London, UK

2 University College London, London, UK 


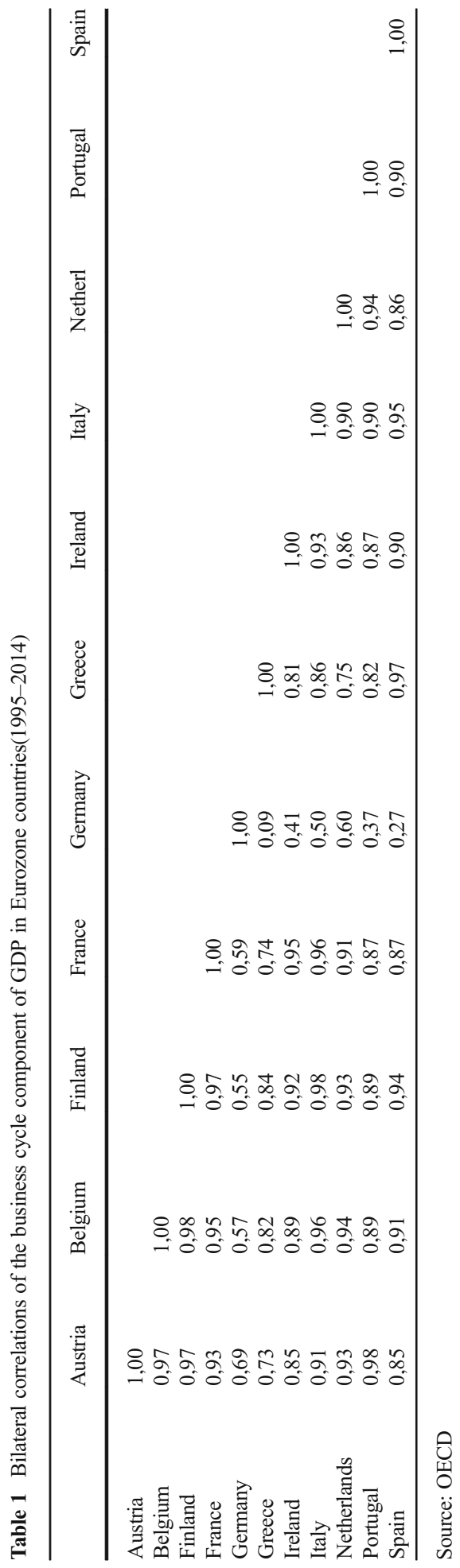




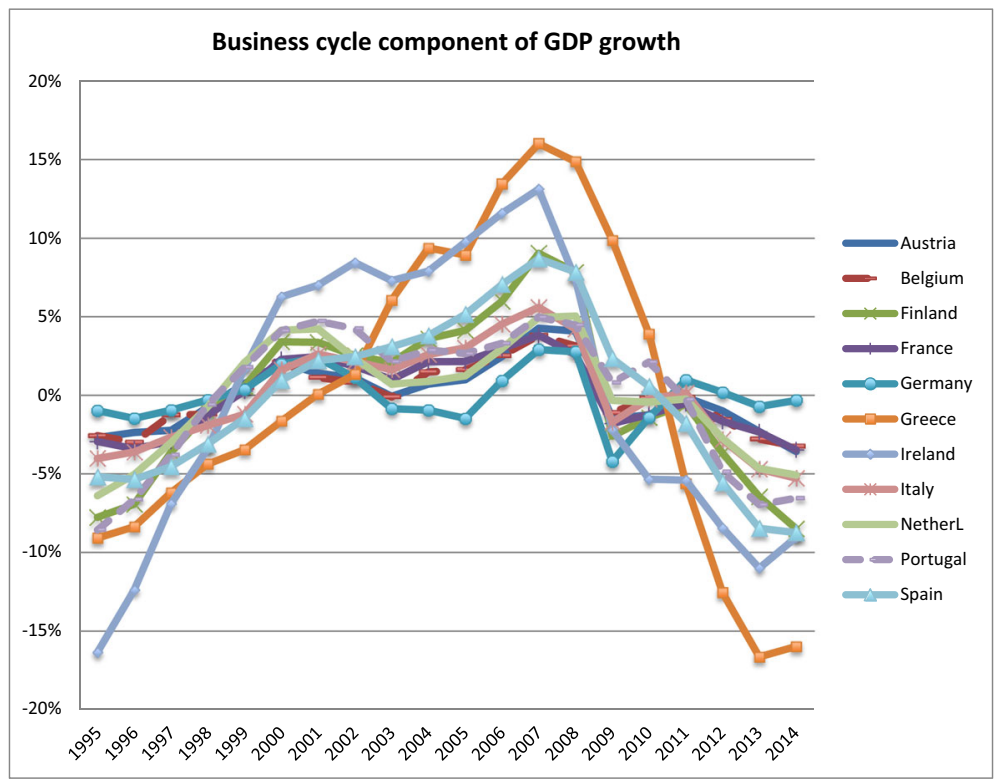

Fig. 1 Business cycle components of GDP growth. Source: De Grauwe and Ji (2016)

components of GDP growth in the Eurozone. This clearly shows that Eurozone countries have experienced more or less the same business cycle movements since 1995. If there is a difference between these countries it is to be found in the amplitude of the business cycle movements (see De Grauwe and Ji 2016 for an analysis of the implications of these different amplitudes). We are aware of the fact that measuring business cycles is fraught with difficulties (see Giannone et al. 2008). However, our findings are consistent with others (see de Haan et al. 2008; Belke et al. 2016).

Outside the Eurozone we observe smaller bilateral correlations of the business cycles than in the Eurozone. However, these correlations can still be called quite high. They often reach levels of 0.6 or more. Poland stands out as the only country with negative correlations. The average of all the correlation coefficients in Table 2 is 0.61 . Thus it appears that in the group of industrial countries outside the Eurozone business cycles are also quite synchronized.

There exists empirical evidence that the degree of synchronization of the business cycles is influenced by the degree of trade integration. Frankel and Rose (1998) found that increasing trade integration leads to more synchronization of the business cycles. This has been confirmed by other empirical studies (see Artis and Cleays 2005; Bordo and Helbling 2004).

Trade integration is one explanatory factor, but it does not explain everything. This is made clear by Figs. 2 and 3 which plot the bilateral correlation coefficients obtained from Tables 1 and 2 with the bilateral trade flows (as a percent of the sum of the GDPs of the pairs of countries involved). We observe that there is a positive relation between the degree of bilateral trade integration and bilateral correlations. This relation, however, is weak and explains only a small fraction of the variation in the bilateral correlations. Clearly there are other mechanisms at work driving the synchronization of business cycles. It is the intention of this paper to uncover these other mechanisms. 


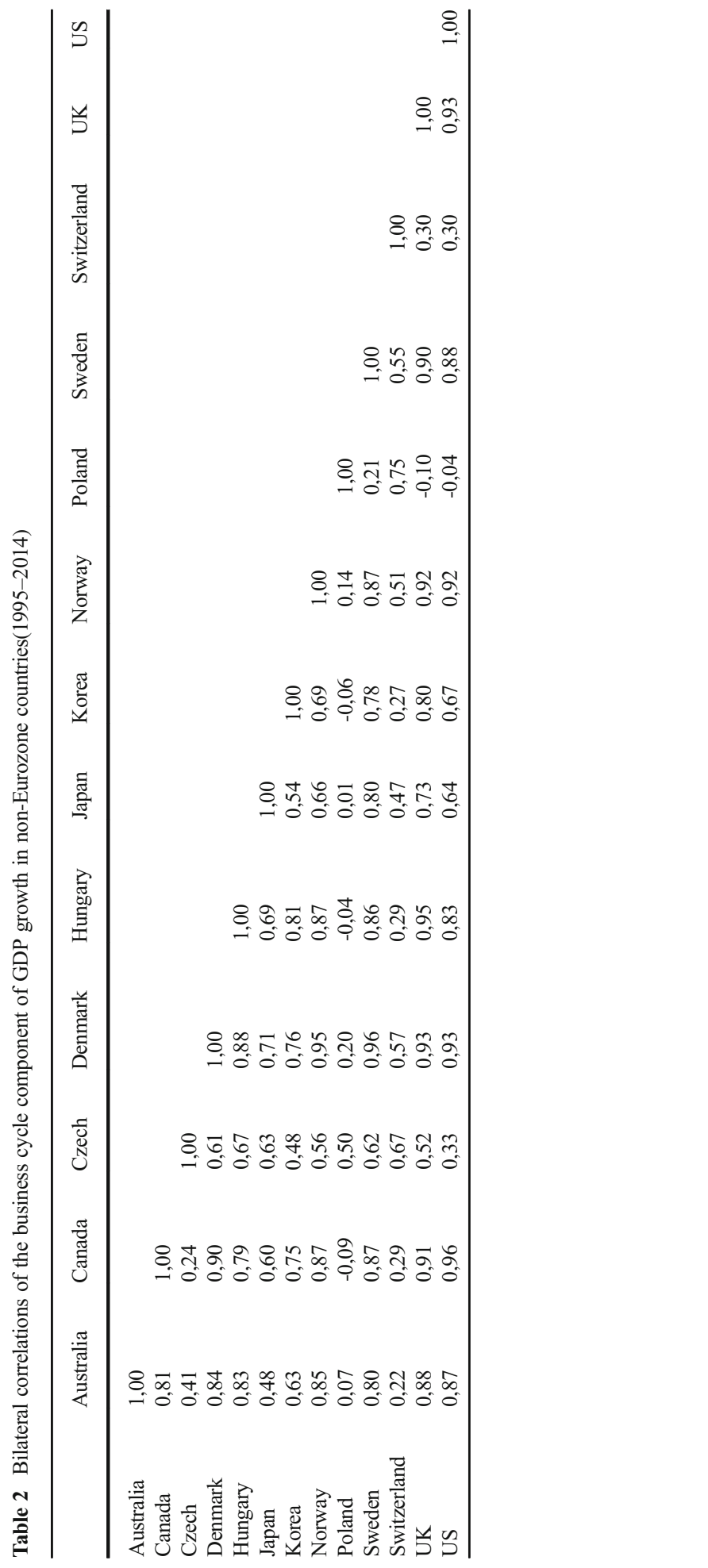




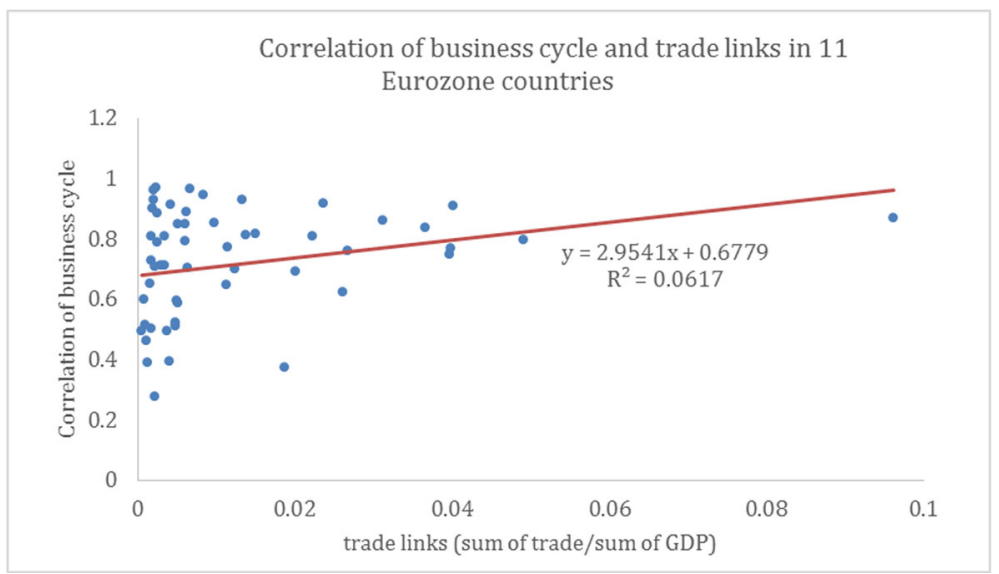

Source: authors' own estimation using data from OECD and IMF, direction of trade

Fig. 2 Correlation of business cycle and trade links in 11 Eurozone countries. Source: authors' own estimation using data from OECD and IMF, direction of trade

Mainstream macroeconomic models (both real business cycle models and DSGE models) have found it difficult to replicate the observed high synchronization of business cycles in the industrialized world. This problem was first pointed out by Backus et al. (1992) who found that standard open economy versions of real business cycle models could not explain the high level of synchronization of the business cycles across countries (see also Canova and Dellas 1993). Open economy versions of DSGE-models have experienced the same problem (see Kollmann 1995; Alpanda and Aysun 2014). Of course one can solve these problems in these models by assuming high positive correlations of exogenous shocks. But this is not really an explanation as it forces the designers of these models to admit that high correlations of the business cycles across countries are produced outside their models. This is not a very satisfactory analysis.

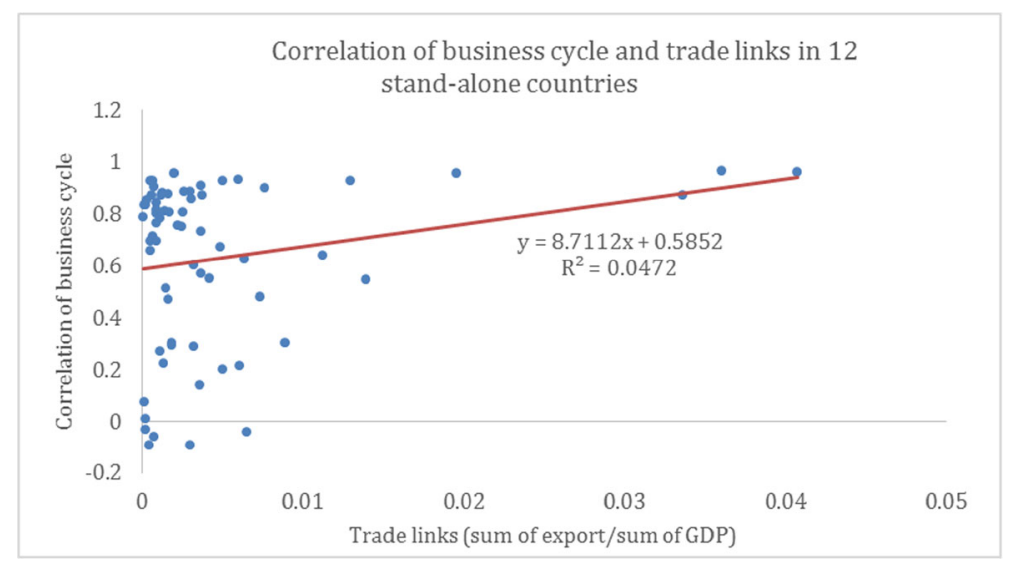

Source: authors' own estimation using data from OECD and IMF, direction of trade

Fig. 3 Correlation of business cycle and trade links in 12 stand-alone countries. Source: authors' own estimation using data from OECD and IMF, direction of trade 
There have been attempts to explain the high synchronization of the business cycles across countries by introducing financial integration in the models (see e.g. Stockman and Tesar 1995; Gertler et al. 2007; Devereux and Yetman 2010; Kollmann, et al. 2012; Alpanda and Aysun 2014). This goes some way in explaining this synchronization. But again too much is "explained" by introducing highly correlated exogenous financial shocks (see Rey 2014).

In this paper we want to go further. We want to analyze the mechanism through which business cycles are synchronized across countries that trade with each other. We will do this using a behavioral macroeconomic model similar to De Grauwe (2012) but in a two-county setting. We will show that the transmission of business cycle movements is made possible by a dynamics that leads to correlation of "animal spirits" across countries. We will develop this model in the context of two different monetary regimes. The first one is a monetary union between the two countries. The second one assumes two "standalone" countries each one with their own central bank.

The rest of the paper is organized as follows. Section 2 presents a two-country version of our behavioral macroeconomic model. Section 3 discusses the solutions of this model and sections 4 uses the model to analyze the factors that affect the international synchronization of the business cycles. Section 5 presents empirical evidence and section 6 concludes.

\section{The two country behavioral model}

\subsection{Model Choice}

Mainstream macroeconomics has been based on two fundamental ideas. The first one is that macroeconomic models should be micro-founded, i.e. they should start from individual optimization and then aggregate these individuals' optimal plans to obtain a general equilibrium model. This procedure leads to intractable and well-known aggregation problems (Sonnenschein 1972; Kirman; 1993) that cannot easily be solved. This has led DSGEmodel builders to circumvent the aggregation problems by introducing the representative agent, i.e. by assuming that demand and supply decisions in the aggregate can be reduced to decisions made at the individual level.

The second idea is that expectations should be rational, i.e. should take all available information into account, including the information about the structure of the economic model and the distribution of the shocks hitting the economy.

These two ideas lead to problems. First, the use of a representative agent has the effect of brushing under the carpet the interesting sources of macroeconomic dynamics which come from the fact that agents are heterogeneous and therefore have different beliefs about the state of the economy. Second, the use of rational expectations implies that individual agents have extraordinary cognitive abilities, which we believe are implausible in a world of great complexity.

Therefore we make a different choice of model. First, we will bring at center stage the heterogeneity of agents in that they have different beliefs about the state of the economy. The price we pay is that we do not microfound the model and assume the existence of aggregate demand and supply equations. Second, we assume that agents have cognitive limitations preventing them from having rational expectations. Instead they will be assumed to follow simple rules of thumb (heuristics). Rationality will be introduced by assuming a willingness 
to learn from mistakes and therefore a willingness to switch between different heuristics. In making these choices we follow the road taken by an increasing number of macroeconomists, which have developed "agent-based models" and "behavioral macroeconomic models" (Tesfatsion 2001; Tesfatsion and Judd 2006; Colander et al. 2008; Farmer and Foley 2009; Gatti et al. 2011; Westerhoff 2012; De Grauwe 2012; Hommes and Lustenhouwer 2016).

\subsection{Basic Model}

Following De Grauwe (2012), we use a simple behavioral macroeconomic model and we extend it to two countries that trade with each other. The basic structure of this behavioural model is the same as the mainstream New-Keynesian model as described in e.g. Galí (2008). The model consists of two aggregate demand equations, two aggregate supply equations and a Taylor rule. To keep the model simple, we assume that the two countries are symmetric and therefore exhibit the same parameters. We will also discuss the model in two monetary regimes, one is in a monetary union with a common central bank and a common short-term interest rate, the other regime is two countries with their own independent central banks and different interest rates. In the second regime, we will have two independent Taylor rules.

The aggregate demand equations for countries 1 and 2 are specified in the standard way, i.e.

$$
\begin{aligned}
& y_{t}^{1}=a_{1} \tilde{E}_{t} y_{t+1}^{1}+\left(1-a_{1}\right) y_{t-1}^{1}+a_{2}\left(r_{t}-\tilde{E}_{t} \pi_{t+1}^{1}\right)+\left(x_{t}^{1}-m_{t}^{1}\right)+\varepsilon_{t}^{1} \\
& y_{t}^{2}=a_{1} \tilde{E}_{t} y_{t+1}^{2}+\left(1-a_{1}\right) y_{t-1}^{2}+a_{2}\left(r_{t}-\tilde{E}_{t} \pi_{t+1}^{2}\right)+\left(x_{t}^{2}-m_{t}^{2}\right)+\varepsilon_{t}^{2}
\end{aligned}
$$

where $y_{t}^{1}$ and $y_{t}^{2}$ are the output gaps for country 1 and 2 in period $\mathrm{t}, r_{t}$. is the nominal interest rate, $\pi_{t}^{1}$ and $\pi_{t}^{2}$ are the rates of inflation for country 1 and 2 in period $\mathrm{t}$, and $\varepsilon_{t}^{1}$ and $\varepsilon_{t}^{2}$ are white noise disturbance terms for country 1 and $2 . \tilde{E}_{t}^{i}$ is the expectations operator where the tilde above $E$ refers to expectations that are not formed rationally. This expectations formations process will be specified subsequently. We follow the procedure introduced in New Keynesian macroeconomic models of adding a lagged output $y_{t-1}^{1}$ and $y_{t-1}^{2}$ in the demand equation (see Galí 2008; Woodford 2003). This is usually justified by invoking habit formation. We also take into account trade links between the two countries: $x_{t}^{1}$ and $x_{t}^{2}$ as the exports of countries 1 and $2, m_{t}^{1}$ and $m_{t}^{2}$ the imports of countries 1 and 2 . These variables are also defined as gaps, i.e. the difference between the actual values and the values obtained in the steady state when the output gap is zero. Assuming that the import propensity, $m$, is the same in both countries and that the two countries only trade with each other, the aggregate demand equations for countries 1 and 2 can be rewritten as follows:

$$
\begin{aligned}
& y_{t}^{1}=\frac{a_{1}}{1+m} \tilde{E}_{t} y_{t+1}^{1}+\frac{1-a_{1}}{1+m} y_{t-1}^{1}+\frac{a_{2}}{1+m}\left(r_{t}-\tilde{E}_{t} \pi_{t+1}^{1}\right)+\frac{m}{1+m} y_{t}^{2}+\frac{\varepsilon_{t}^{1}}{1+m} \\
& y_{t}^{2}=\frac{a_{1}}{1+m} \tilde{E}_{t} y_{t+1}^{2}+\frac{1-a_{1}}{1+m} y_{t-1}^{2}+\frac{a_{2}}{1+m}\left(r_{t}-\tilde{E}_{t} \pi_{t+1}^{2}\right)+\frac{m}{1+m} y_{t}^{1}+\frac{\varepsilon_{t}^{2}}{1+m}
\end{aligned}
$$

The aggregate supply equation aggregate demand equation has a very simple interpretation. Utility maximizing agents will want to spend more on goods and services today when 
they expect future income (output gap) to increase and to spend less when the real interest rate increases. Moreover, the existence of trade between the two countries creates a positive link between the output gaps of these countries.

We should stress that we make a strong simplifying assumption. We consider the import propensity, $\mathrm{m}$, to be constant. This implies that import and export decisions are not sensitive to relative price changes. We plan to relax this assumption in future research.

We assume an aggregate supply equation of the New Keynesian Philips curve type. In addition, it is assumed that producers cannot adjust their prices instantaneously. Instead, for institutional reasons, they have to wait to adjust their prices. The most popular specification of this price adjustment mechanism is the Calvo pricing mechanism (Calvo 1983). This assumes that in period $t$, a fraction of prices remains unchanged. Under those conditions the aggregate supply equation for countries 1 and 2 can be written as:

$$
\begin{aligned}
& \pi_{t}^{1}=b_{1} \tilde{E}_{t} \pi_{t+1}^{1}+\left(1-b_{1}\right) \pi_{t+1}^{1}+b_{2} y_{t}^{1}+\eta_{t}^{1} \\
& \pi_{t}^{2}=b_{1} \tilde{E}_{t} \pi_{t+1}^{2}+\left(1-b_{1}\right) \pi_{t+1}^{2}+b_{2} y_{t}^{2}+\eta_{t}^{2}
\end{aligned}
$$

Equations (3)-(6) determine the four endogenous variables, inflation $\pi_{t}^{1}$ and $\pi_{t}^{2}$, and output gap $\mathrm{y}_{t}^{1}$ and $\mathrm{y}_{t}^{2}$, given the nominal interest rate $r_{t}$. The model has to be closed by specifying the way the nominal interest rate is determined. The most popular way to do this has been to invoke the Taylor rule (see Taylor (1993)) that describes the behavior of the central bank. In a monetary union, this rule is written as follows:

$$
r_{t}=c_{1}\left(\overline{\pi_{t}}-\pi^{*}\right)+c_{2} \overline{y_{t}}+c_{3} r_{t-1}+u_{t}
$$

where $\overline{\pi_{t}}=\frac{1}{2}\left(\pi_{t}^{1}+\pi_{t}^{2}\right)$ and $\overline{y_{t}}=\frac{1}{2}\left(y_{t}^{1}+y_{t}^{2}\right), \pi^{*}$ is the inflation target and we will assume it is zero. Thus the central bank is assumed to raise the interest when the observed inflation rate increases relative to the announced inflation target. The intensity with which it does this is measured by the coefficient $c_{1}$. It has been shown (see Woodford 2003 or Galí 2008) that it must exceed 1 for the model to be stable. This is also sometimes called the "Taylor principle". 1

When the output gap increases the central bank is assumed to raise the interest rate. The intensity with which it does this is measured by $c_{2}$. The latter parameter then also tells us something about the ambitions the central bank has to stabilize output. A central bank that does not care about output stabilization sets $\mathrm{c}_{2}=0$. We say that this central bank applies strict inflation targeting. Finally, note that, as is commonly done, the central bank is assumed to smooth the interest rate. This smoothing behavior is represented by the lagged interest rate in Eq. (7).

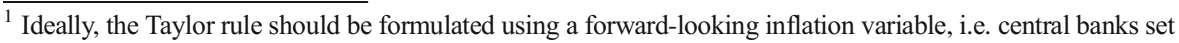
the interest rate on the basis of their forecasts about the rate of inflation. This is not done here in order to maintain simplicity in the model (again see Woodford 2003, p. 257). As is shown in Woodford (2003) forward looking Taylor rules may not lead to a determinate solution even if the Taylor principle is satisfied. See also Blatner and Margaritov(2010)
} 
We have added error terms in each of the equations. These error terms describe the nature of the different shocks that can hit the economy. There are demand shocks $\varepsilon_{t}^{1}$ and $\varepsilon_{t}^{2}$, supply shocks $\eta_{t}^{1}$ and $\eta_{t}^{2}$, and interest rate shocks, $u_{t}$. We will generally assume that these shocks are normally distributed with mean zero and a constant standard deviation. We will allow these shocks to be correlated across countries.

As mentioned earlier, we will also want to apply this model in a regime in which the two countries are not member of a monetary union, i.e. they have their own independent central banks and two short term interest rates. Accordingly, the aggregate demand equations can then be rewritten as:

$$
\begin{aligned}
& y_{t}^{1}=\frac{a_{1}}{1+m} \tilde{E}_{t} y_{t+1}^{1}+\frac{1-a_{1}}{1+m} y_{t-1}^{1}+\frac{a_{2}}{1+m}\left(r_{t}^{1}-\tilde{E}_{t} \pi_{t+1}^{1}\right)+\frac{m}{1+m} y_{t}^{2}+\frac{\varepsilon_{t}^{1}}{1+m} \\
& y_{t}^{2}=\frac{a_{1}}{1+m} \tilde{E}_{t} y_{t+1}^{2}+\frac{1-a_{1}}{1+m} y_{t-1}^{2}+\frac{a_{2}}{1+m}\left(r_{t}^{2}-\tilde{E}_{t} \pi_{t+1}^{2}\right)+\frac{m}{1+m} y_{t}^{1}+\frac{\varepsilon_{t}^{2}}{1+m}
\end{aligned}
$$

The Taylor rule in each central bank can be written as follows:

$$
\begin{aligned}
& r_{t}^{1}=c_{1}\left(\pi_{t}^{1}-\pi^{*}\right)+c_{2} y_{t}^{1}+c_{3} r_{t-1}^{1}+u_{t}^{1} \\
& r_{t}^{2}=c_{1}\left(\pi_{t}^{2}-\pi^{*}\right)+c_{2} y_{t}^{2}+c_{3} r_{t-1}^{2}+u_{t}^{2}
\end{aligned}
$$

Clearly in this version of the model there is an exchange rate that will vary as central banks set their interest rates independently. We will disregard this exchange rate channel here and leave this for further research.

\subsection{Introducing Heuristics in Forecasting Output and Inflation}

In the world of rational expectations that forms the basis of the mainstream model agents are assumed to understand the complexities of the world. In contrast, we take the view that agents have cognitive limitations. They only understand tiny little bits of the world. In such a world agents are likely to use simple rules, heuristics, to forecast the future (see e.g. Damasio 2003; Kahneman 2002; Camerer et al. 2005).

Agents who use simple rules of behavior are not irrational. They use simple rules only because the real world is too complex to understand, but they are willing to learn from their mistakes, i.e. they regularly subject the rules they use to some criterion of success. This leads to the concept of adaptive learning.

Adaptive learning is a procedure whereby agents use simple forecasting rules and then subject these rules to a "fitness" test, i.e., agents endogenously select the forecasting rules that have delivered the highest performance ("fitness") in the past. Thus, an agent will start using one particular rule. She will regularly evaluate this rule against the alternative rules. If the former rule performs well, she keeps it. If not, she switches to another rule. In this sense the rule can be called a "trial and error" rule. 
This "trial and error" selection mechanism acts as a disciplining device on the kind of rules that are acceptable. Not every rule is acceptable. It has to perform well. What that means will be made clear later. It is important to have such a disciplining device, otherwise everything becomes possible. The need to discipline the forecasting rule was also one of the basic justifications underlying rational expectations. By imposing the condition that forecasts must be consistent with the underlying model, the model builder severely limits the rule that agents can use to make forecasts. The adaptive selections mechanism used here plays a similar disciplining role.

Agents are assumed to use simple rules (heuristics) to forecast the future output and inflation. The way we proceed is as follows. We assume two types of forecasting rules. A first rule can be called a "fundamentalist" one. Agents estimate the steady state value of the output gap (which is normalized at 0 ) and use this to forecast the future output gap. ${ }^{2}$ A second forecasting rule is an "extrapolative" one. This is a rule that does not presuppose that agents know the steady state output gap. They are agnostic about it. Instead, they extrapolate the previous observed output gap into the future.

The two rules that are followed in the two countries are specified as follows:

The fundamentalist rule is defined by $\tilde{E}_{t}^{f} y_{t+1}=0$

The extrapolative rule is defined by $\tilde{E}_{t}^{e} y_{t+1}=y_{t-1}$

We have dropped the country superscripts here (and in what follows). Thus Eqs. (12) and (13) apply to agents in both countries.

This kind of simple heuristic has often been used in the behavioral finance literature where agents are assumed to use fundamentalist and chartist rules (see Brock and Hommes 1997; Branch and Evans 2006; De Grauwe and Grimaldi 2006). The rules are simple in the sense that they only require agents to use information they understand, and do not require them to understand the whole picture. Some experimental evidence in support of the two rules similar to (12) and (13) for inflation forecasts in a New Keynesian model can be found in a paper by Pfajfar and Žakelj (2009). For a survey of the experimental evidence see Hommes (2016).

The market forecast is obtained as a weighted average of these two forecasts, i.e.

$$
\begin{gathered}
\tilde{E}_{t} y_{t+1}=\alpha_{f, t} \tilde{E}_{t}^{f} y_{t+1}+\alpha_{c, t} \tilde{E}_{t}^{e} y_{t+1} \\
\tilde{E}_{t} y_{t+1}=\alpha_{f, t} 0+\alpha_{c, t} y_{t-1}
\end{gathered}
$$

where $\alpha_{f, t}$ and $\alpha_{e, t}$ are the probabilities that agents use a fundamentalist, respectively, an extrapolative rule and $\alpha_{f, t}+\alpha_{e, t}=1$.

\footnotetext{
${ }^{2}$ In De Grauwe (2012) this rule is extended to the case in which agents do not know the steady state output gap with certainty and only have biased estimates of it. This is also done in Hommes and Lustenhouwer (2016).
} 


\subsubsection{Selecting the Forecasting Rules}

As indicated earlier, agents in our model are willing to learn, i.e. they continuously evaluate their forecast performance. This willingness to learn and to change one's behavior is the most fundamental definition of rational behavior. Our agents are rational in the sense that they learn from their mistakes. The concept of "bounded rationality" is often used to characterize this behavior (Simon 1957; Kahneman 2002; Gigerenzer and Selten 2002).

The first step in the analysis then consists in defining a criterion of success. This will be the forecast performance of a particular rule. Thus in this first step, agents compute the forecast performance of the two different forecasting rules as follows:

$$
\begin{aligned}
U_{f, t} & =-\sum_{k=0}^{\infty} \omega_{k}\left[y_{t-k-1}-\tilde{E}_{f, t-k-2} y_{t-k-1}\right]^{2} \\
U_{e, t} & =-\sum_{k=0}^{\infty} \omega_{k}\left[y_{t-k-1}-\tilde{E}_{e, t-k-2} y_{t-k-1}\right]^{2}
\end{aligned}
$$

where $U_{f, t}$ and $U_{e, t}$ are the utilities obtained from the fundamentalist and extrapolating rules, respectively. These are defined as the negative of the mean squared forecasting errors (MSFEs) of the forecasting rules; $\omega_{k}$ are geometrically declining weights. We make these weights declining because we assume that agents tend to forget. Put differently, they give a lower weight to errors made far in the past as compared to errors made recently.

The next step consists in evaluating these forecast performances (utilities). We apply discrete choice theory (see Anderson et al. 1992 for a thorough analysis of discrete choice theory and Brock and Hommes 1997 for the first application in finance) in specifying the procedure agents follow in this evaluation process. If agents were purely rational they would just compare $U_{f, t}$ and $U_{e, t}$ in (16) and (17) and choose the rule that produces the highest value. Thus under pure rationality, agents would choose the fundamentalist rule if $U_{f, t}>U_{e, t}$, and vice versa. However, psychologists have found out that when we have to choose among alternatives we are also influenced by our state of mind. The latter is to a large extent unpredictable. It can be influenced by many things, the weather, recent emotional experiences, etc. One way to formalize this is that the utilities of the two alternatives have a deterministic component (these are $U_{f, t}$ and $U_{e, t}$ in (16) and (17)) and a random component $\varepsilon_{f, t}$ and $\varepsilon_{e, t}$ The probability of choosing the fundamentalist rule is then given by

$$
\alpha_{f, t}=P\left[\left(U_{f, t}+\varepsilon_{f, t}\right)>\left(U_{e, t}+\varepsilon_{e, t}\right)\right]
$$

In words, this means that the probability of selecting the fundamentalist rule is equal to the probability that the stochastic utility associated with using the fundamentalist rule exceeds the stochastic utility of using an extrapolative rule. In order to derive a more precise expression one has to specify the distribution of the random variables $\varepsilon_{f, t}$ and $\varepsilon_{e, t}$ . It is customary in the discrete choice literature to assume that these random variables 
are logistically distributed (see Anderson et al. (1992), p. 35). One then obtains the following expressions for the probability of choosing the fundamentalist rule:

$$
\alpha_{f, t}=\frac{\exp \left(\gamma U_{f, t}\right)}{\exp \left(\gamma U_{f, t}\right)+\exp \left(\gamma U_{e, t}\right)}
$$

Similarly the probability that an agent will use the extrapolative forecasting rule is given by:

$$
\alpha_{e, t}=\frac{\exp \left(\gamma U_{e, t}\right)}{\exp \left(\gamma U_{f, t}\right)+\exp \left(\gamma U_{e, t}\right)}=1-\alpha_{f, t}
$$

Equation (19) says that as the past forecast performance of the fundamentalist rule improves relative to that of the extrapolative rule, agents are more likely to select the fundamentalist rule for their forecasts of the output gap. Equation (20) has a similar interpretation. The parameter $\gamma$ measures the "intensity of choice". It is related to the variance of the random components $\varepsilon_{f, t}$ and $\varepsilon_{e, t}$. If the variance is very high, $\gamma$ approaches 0 . In that case agents decide to be fundamentalist or extrapolator by tossing a coin and the probability to be fundamentalist (or extrapolator) is exactly 0.5 . When $\gamma=\infty$ the variance of the random components is zero (utility is then fully deterministic) and the probability of using a fundamentalist rule is either 1 or 0 . The parameter $\gamma$ can also be interpreted as expressing a willingness to learn from past performance. When $\gamma=0$ this willingness is zero; it increases with the size of $\gamma$.

It should be mentioned here that the probabilities $\alpha_{f, t}$ and $\alpha_{e, t}$ can also be interpreted as the fractions of agents that use a fundamentalist and extrapolative forecasting rule, respectively. This can be seen as follows. Suppose the number of agents is $N$. Then, if the probability that an agent uses a fundamentalist rule is $\alpha_{f, t}$, on average $\alpha_{f, t} N$ agents will use this rule. Thus the fraction of the total number of agents using this rule is $\frac{\alpha_{\mathrm{ft}} N}{N}=\alpha_{f, t}$. The same holds for $\alpha_{e, t}$. These fractions are determined by the rules (19) and (20) and are time dependent. This illustrates an important feature of the model, i.e. the heterogeneity of beliefs and their shifting nature over time.

As argued earlier, the selection mechanism used should be interpreted as a learning mechanism based on "trial and error". When observing that the rule they use performs less well than the alternative rule, agents are willing to switch to the more performing rule. Put differently, agents avoid making systematic mistakes by constantly being willing to learn from past mistakes and to change their behavior. This also ensures that the market forecasts are unbiased.

\subsubsection{Heuristics and Selection Mechanism in Forecasting Inflation}

Agents also have to forecast inflation. A similar simple heuristics is used as in the case of output gap forecasting, with one rule that could be called a fundamentalist rule and the other an extrapolative rule. (See Brazier et al. (2006) for a similar setup). We assume an institutional set-up in which the central bank announces an explicit inflation target. The fundamentalist rule then is based on this announced inflation target, i.e. 
agents using this rule have confidence in the credibility of this rule and use it to forecast inflation. Agents who do not trust the announced inflation target use the extrapolative rule, which consists in extrapolating inflation from the past into the future.

The fundamentalist rule will be called an "inflation targeting" rule. It consists in using the central bank's inflation target to forecast future inflation, i.e.

$$
\tilde{E}_{t}^{\text {tar }} \pi_{t+1}=\pi^{*}
$$

where the inflation target $\pi^{*}$ is normalized to be equal to 0 . The "extrapolators" are defined by

$$
E_{t}^{e x t} \pi_{t+1}=\pi_{t-1}
$$

The market forecast is a weighted average of these two forecasts, i.e.

$$
\tilde{E}_{t} \pi_{t+1}=\beta_{\text {tar }, t} \tilde{E}_{t}^{\text {tar }} \pi_{t+1}+\beta_{\text {ext }, t} \tilde{E}_{t}^{e x t} \pi_{t+1}
$$

or

$$
\tilde{E}_{t} \pi_{t+1}=\beta_{\text {tar }, t} \pi^{*}+\beta_{\text {ext }, t} \pi_{t-1}
$$

and

$$
\beta_{\text {tar }, t}+\beta_{\text {ext }, t}=1
$$

The same selection mechanism is used as in the case of output forecasting to determine the probabilities of agents trusting the inflation target and those who do not trust it and revert to extrapolation of past inflation, i.e.

$$
\begin{aligned}
& \beta_{\text {tar }, t}=\frac{\exp \left(\gamma U_{\text {tar }, t}\right)}{\exp \left(\gamma U_{\text {tar }, t}\right)+\exp \left(\gamma U_{\text {ext }, t}\right)} \\
& \beta_{\text {ext }, t}=\frac{\exp \left(\gamma U_{\text {ext }, t}\right)}{\exp \left(\gamma U_{\text {tar }, t}\right)+\exp \left(\gamma U_{\text {ext }, t}\right)}
\end{aligned}
$$

where $U_{\text {tar, } t}$ and $U_{\text {ext, } t}$ are the forecast performances (utilities) associated with the use of the fundamentalist and extrapolative rules. These are defined in the same way as in (16) and (17), i.e. they are the negatives of the weighted averages of past squared forecast errors of using fundamentalist (inflation targeting) and extrapolative rules, respectively.

This inflation forecasting heuristics can be interpreted as a procedure of agents to find out how credible the central bank's inflation targeting is. If this is very credible, using the announced inflation target will produce good forecasts and as a result, the probability that agents will rely on the inflation target will be high. If on the other hand the inflation target does not produce good forecasts (compared to a simple extrapolation rule) the probability that agents will use it will be small. 


\subsection{Defining Animal Spirits}

The forecasts made by extrapolators and fundamentalists play an important role in the model. In order to highlight this role we derive an index of market sentiments from the endogenously obtained fractions $\alpha_{e, t}$ and $\alpha_{f, t}$. We will call these "animal spirits"(Keynes 1936; Farmer 2006; Akerlof and Shiller 2009). They reflect how optimistic or pessimistic these forecasts are, and they are obtained endogenously from the model.

The definition of animal spirits is as follows:

$$
S_{t}= \begin{cases}\alpha_{e, t}-\alpha_{f, t} & \text { if } y_{t-1}>0 \\ -\alpha_{e, t}+\alpha_{f, t} & \text { if } y_{t-1}<0\end{cases}
$$

where $S_{t}$ is the index of animal spirits. This can change between -1 and +1 . There are two possibilities:

- When $y_{t-1}>0$, extrapolators forecast a positive output gap. The fraction of agents who make such a positive forecasts is $\alpha_{e, t}$. Fundamentalists, however, then make a pessimistic forecast since they expect the positive output gap to decline towards the equilibrium value of 0 . The fraction of agents who make such a forecast is $\alpha_{f, t}$. We subtract this fraction of pessimistic forecasts from the fraction $\alpha_{e, t}$ who make a positive forecast. When these two fractions are equal to each other (both are then 0.5) market sentiments (animal spirits) are neutral, i.e. optimists and pessimists cancel out and $S_{t}=0$. When the fraction of optimists $\alpha_{e, t}$ exceeds the fraction of pessimists $\alpha_{f, t}, S_{t}$ becomes positive. As we will see, the model allows for the possibility that $\alpha_{e, t}$ moves to 1 . In that case there are only optimists and $S_{t}=1$.

- When $y_{t-1}<0$, extrapolators forecast a negative output gap. The fraction of agents who make such a negative forecasts is $\alpha_{e, t}$. We give this fraction a negative sign. Fundamentalists, however, then make an optimistic forecast since they expect the negative output gap to increase towards the equilibrium value of 0 . The fraction of agents who make such a forecast is $\alpha_{f, t}$. We give this fraction of optimistic forecasts a positive sign. When these two fractions are equal to each other (both are then 0.5 ) market sentiments (animal spirits) are neutral, i.e. optimists and pessimists cancel out and $S_{t}=0$. When the fraction of pessimists $\alpha_{e, t}$ exceeds the fraction of optimists $\alpha_{f, t} S_{t}$ becomes negative. The fraction of pessimists, $\alpha_{e, t}$, can move to 1. In that case there are only pessimists and $S_{t}=-1$.

We can rewrite $(28)$ as follows ${ }^{3}$ :

$$
S_{t}= \begin{cases}\alpha_{e, t}-\left(1-\alpha_{e, t}\right)=2 \alpha_{e, t}-1 & \text { if } y_{t-1}>0 \\ -\alpha_{e, t}+\left(1-\alpha_{e, t}\right)=-2 \alpha_{e, t}+1 & \text { if } y_{t-1}<0\end{cases}
$$

\footnotetext{
${ }^{3}$ In De Grauwe (2012) animal spirits are defined so as to move between 0 and 1 . It can be shown that the animal sprits defined here are the same apart from a linear transformation that allows the animal sprits index to move between -1 and +1 .
} 
It should be noted that these animal spirits are unrelated to "sunspot equilibria" in the sense of Cass and Shell (1983). The latter arise because of the existence of a random variable individuals believe matters for the economic outcome. Our animal spirits arise endogenously as a result of agents with cognitive limitations switching between different heuristics in search of the best possible forecast.

\subsection{Solution of the Model}

The solution procedure of the model is described in appendix 1. As the model is highly non-linear we calibrate it and use numerical methods to solve it. The table with the numerical values given to the coefficients, and which we obtain from the literature (see e.g. Galí (2008)) is presented in appendix 2. We will perform extensive sensitivity analysis to check the robustness of our results.

\section{Results of the Model: the Basics}

In this section we present some of the basic results of simulating the model using the calibration discussed in the previous section. We present the results both for the monetary union model (one central bank) and the monetary independence model (two-country model with separate central banks).

\subsection{Monetary Union Model}

We first present the results of the simulation exercises in the time domain. This will allow us to understand the dynamics produced by the model. In the next sections we perform sensitivity analyses. Figure 4 presents the simulated output gaps in the two countries. We find a relatively high correlation of these output gaps between the two countries. This correlation is 0.95 . Underlying this is an import propensity $(\mathrm{m})$ of 0.3 and a correlation of the exogenous demand shocks of 0.2. Thus the model produces a synchronization of the business cycle that adds to the trade integration effect and the existence of correlated exogenous demand shocks. The additional synchronization comes from "the animal spirits".
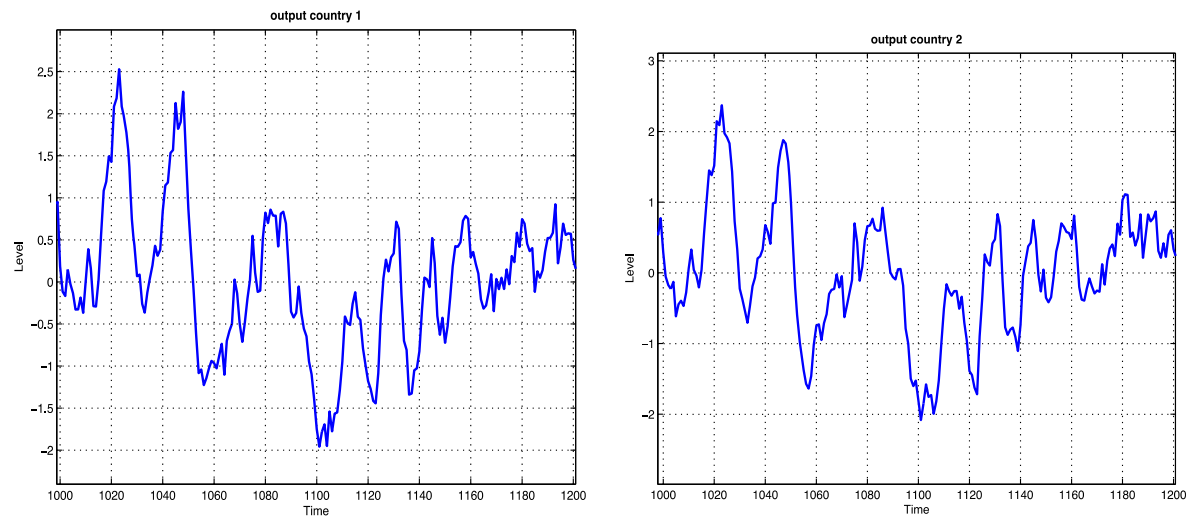

Fig. 4 Simulation of the output gaps in countries 1 and 2 

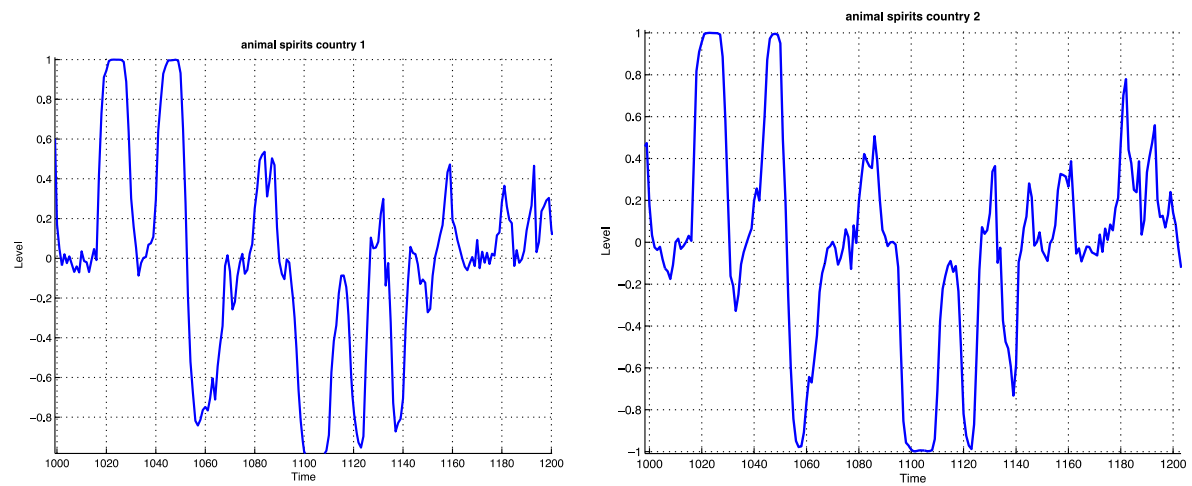

Fig. 5 Simulation of the animal spirits in countries 1 and 2

These are shown in Fig. 5. As explained in the previous section, the "animal spirits" measure market sentiments, i.e. optimism and pessimism in forecasting.

We observe that the model produces waves of optimism and pessimism that can lead to a situation where everybody becomes optimist $\left(S_{t}=1\right)$ or pessimist $\left(S_{t}=-1\right)$. These waves of optimism and pessimism are generated endogenously and arise because optimistic (pessimistic) forecasts are self-fulfilling and therefore attract more agents into being optimists (pessimists).

The correlation of these animal spirits and the output gap is high. In the simulations reported in Fig. 5 this correlation reaches 0.94 . Underlying this correlation is the selffulfilling nature of expectations. When a wave of optimism is set in motion, this leads to an increase in aggregate demand (see Eq. 1). This increase in aggregate demand leads to a situation in which those who have made optimistic forecasts are vindicated. This attracts more agents using optimistic forecasts. This leads to a self-fulfilling dynamics in which most agents become optimists. It is a dynamics that leads to a correlation of the same beliefs.

The reverse is also true. A wave of pessimistic forecasts can set in motion a selffulfilling dynamics leading to a downturn in economic activity (output gap). At some point most of the agents have become pessimists.

It now appears that the model produces an international contagion of animal spirits. This is seen from the same Fig. 5 showing the animal spirits in both countries. These animal spirits are highly correlated between the two countries reaching 0.95 . The mechanism that produces this can be described as follows. When a wave of optimism is set in motion in country 1 , it leads to more output and imports in that country, thereby increasing output in country 2. This positive transmission, even if small, makes it more likely that agents in country 2 that make optimistic forecasts are vindicated, thereby increasing the fraction of agents in country 2 that become optimists. Thus we obtain a transmission dynamics that although triggered by trade flows is amplified and leads to a strong synchronization of the business cycles across countries. In section 4 we will give more precise information on the relative importance of trade and animal spirits in producing synchronization of business cycles.

The previous analysis has identified the dynamics that leads to strong synchronization of the business cycle across countries in a monetary union. This dynamics is based on the international contagion of optimism and pessimism (animal spirits) in a 
monetary union. Is this contagion also present in countries that have a separate currency and their own central bank? This question is discussed in the next section.

\subsection{Monetary Independence Model}

In this section we present the result for the two-country model with two independent central banks. In Figs. 6 and 7 we present the results of simulating the model assuming two currencies and two separate central banks. Figure 6 shows the movements of the output gaps in the two countries and Figs. 7 the animal spirits in these two countries. We observe a similar dynamics as in the previous section. The correlation between the output gaps in the two countries, however, is smaller, i.e. 0.73 (versus 0.95 in the previous section). This has to do with the lower correlation of animal spirits between the two countries, i.e. 0.70 , (versus 0.94 in the previous section). Nevertheless it is interesting to find that the behavioral model also produces a strong synchronization of the business cycles across countries that have maintained their own currencies.

It should be mentioned that we produce simulation results assuming the same parameter values of the model in both monetary regimes. In particular, we assume the same degree of trade integration and the same correlation of the exogenous shocks. Thus, the lower correlation of output gaps obtained here compared to the monetary union must be due to other factors. We will show in the next section that the difference in correlation of output gaps and animals spirits across countries has to do with the existence of one central bank in the monetary union model, and two central banks in the second model.

\section{Results of the Model: Factors Affecting Correlation of Business Cycle}

In this section we analyze the factors that influence the correlation of the business cycles across countries. We do this by presenting sensitivity analyses, i.e. we study how the correlations of the output gaps between the two countries are influenced by a number of important parameters of the model. We will focus on trade integration, the correlations of exogenous shocks, and the degree of stabilization of the output gap by the common central bank. We do this for the two monetary regimes, i.e. monetary union and separate central bank.
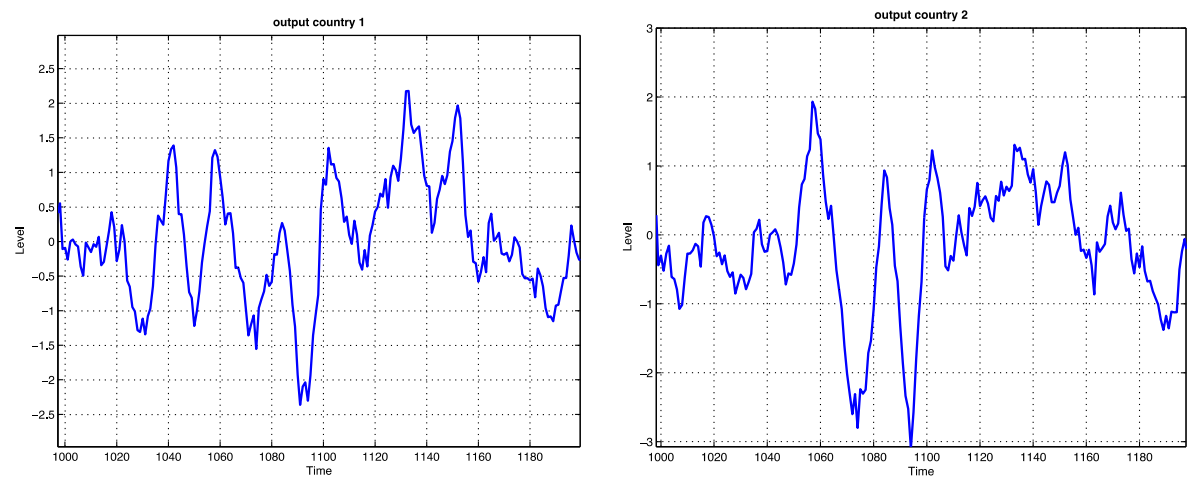

Fig. 6 Simulation of the output gaps in countries 1 and 2 

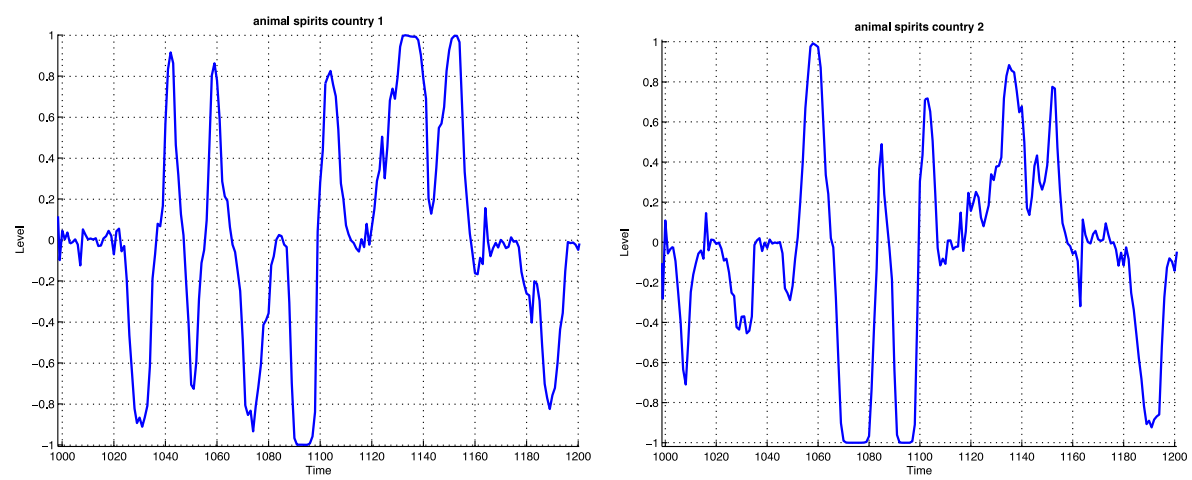

Fig. 7 Simulation of the animal spirits in countries 1 and 2

\subsection{Monetary Union Model and Trade Integration}

We first focus on how trade integration (measured by the import propensities, $m$ ) affects the correlation of output gaps and animal spirits across countries. We show the results in Figs. 8 and 9. On the horizontal axis we set out the import propensities and allow it to change from 0 to 1 . On the vertical axis we set out the correlation of output gaps between the two countries (Fig. 8) and the correlation of animal spirits (Fig. 9) that we obtain in the model for each value of $m$. We find strikingly that even when there is no trade between the two countries $(m=0)$ the model produces positive correlations of output gaps and animal spirits. As trade integration increases the degree of correlation increases. This relation is highly non-linear. When $\mathrm{m}$ increases the correlations increase very fast and then level off for values of $m$ equal to approximately 0.4. Further trade integration has very little additional impact on the synchronization of the business cycles.

Two results stand out here. First the fact that even in the absence of trade there is some synchronization of the business cycles and of animal spirits. This has to do with the fact that underlying this result is a positive correlation of exogenous demand shocks (0.2). We discuss the importance of varying this parameter in the next section.

Fig. 8 Correlation of output gaps and import propensities

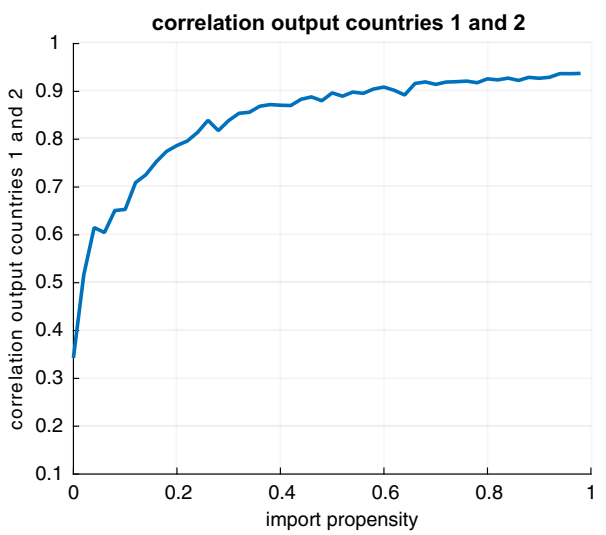


Fig. 9 Correlation of animal spirits and import propensities

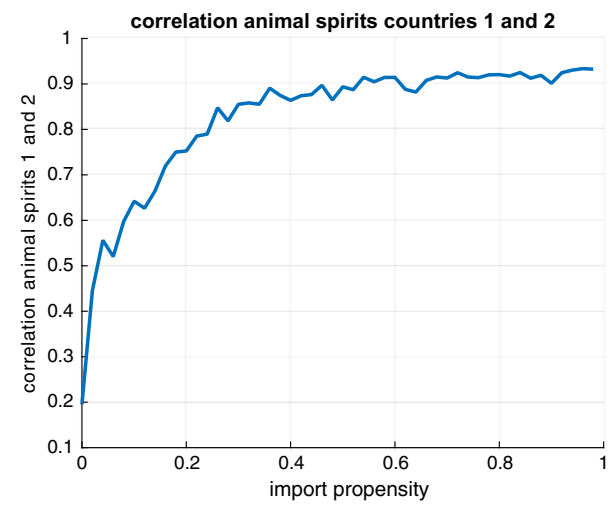

The other interesting result is the non-linear relation between the intensity of trade and the synchronization of the business cycles. Most of the synchronization is reached for relatively low levels of trade integration. Thus relatively low levels of trade are enough to trigger the contagion of animal spirits and through this channel the synchronization of the business cycles. This may explain why we find that among a group of highly integrated industrial countries increasing integration has only weak effects on the correlation of output (see Figs. 2 and 3).

\subsection{Monetary Independence Model and Trade Integration}

Figures 10 and 11 show the results of the sensitivity of the synchronization of the business cycle with respect to trade integration in the two-country model with two central banks. The results are qualitatively similar to the results in a monetary union, i.e. the non-linear relation between synchronization and import propensity. The difference lies in the fact that for each value of $m$ the corresponding correlation is lower than in the monetary union case.

\subsection{Synchronization of Business Cycles and Correlation of Shocks}

Figures 12 and 13 show the sensitivity of the synchronization of business cycles to the correlation of shocks in the monetary union (left panels) and in the monetary independence

Fig. 10 Correlation of output gaps and import propensity

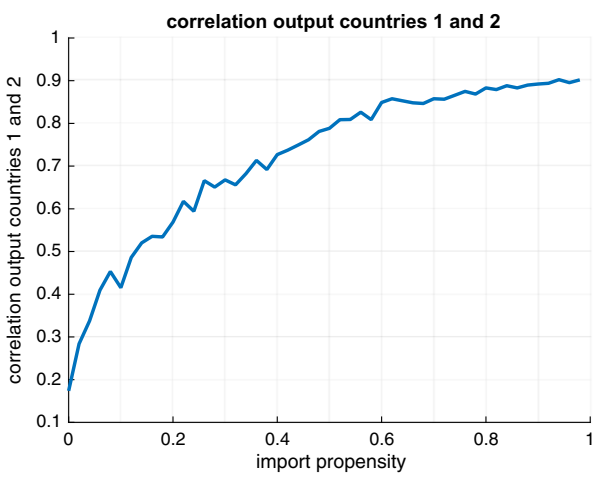


Fig. 11 Correlation of animal spirits and import propensity

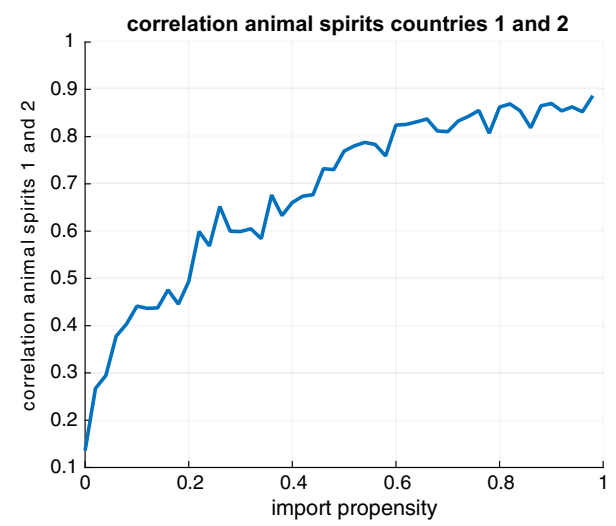

model (right panels). We assume shocks both in the demand and supply equations. We vary the correlation between -1 and 1 . The vertical axes as before show the correlations of output gaps and animal spirits across countries.

The most surprising aspect of these results is that with a perfectly negative correlation of the shocks, the correlation of animal spirits is still positive (approximately 0.2) in a monetary union. As a result, the correlation of output gaps is not -1 (as one may have expected), but approximately -0.6 .

Where does this come from? The answer is the existence of one central bank. The latter sets an interest rate that is the same for both countries according to the Taylor rule. This interest rate setting relation is also subject to random shocks. But since the same rule applies to both countries one has a source of common shocks in these two countries. This then allows animal spirits to be positively correlated even if all the other shocks are negatively correlated.

In both cases we observe again a non-linearity in the relation between correlation of shocks and the correlation of the output gaps. This non-linearity is most pronounced in the monetary union: small declines in the (negative) correlation of the shocks leads to a quick increase in the synchronization of the business cycles (correlation of output gaps). As a

\section{Monetary union}

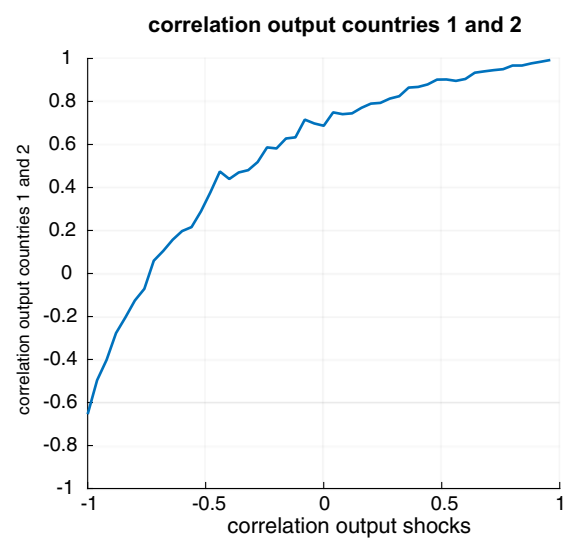

Monetary independence

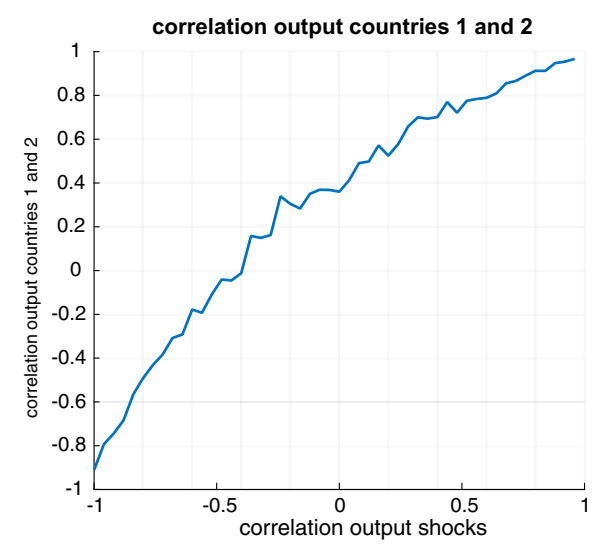

Fig. 12 Correlation output and correlation of shocks 


\section{Monetary union}

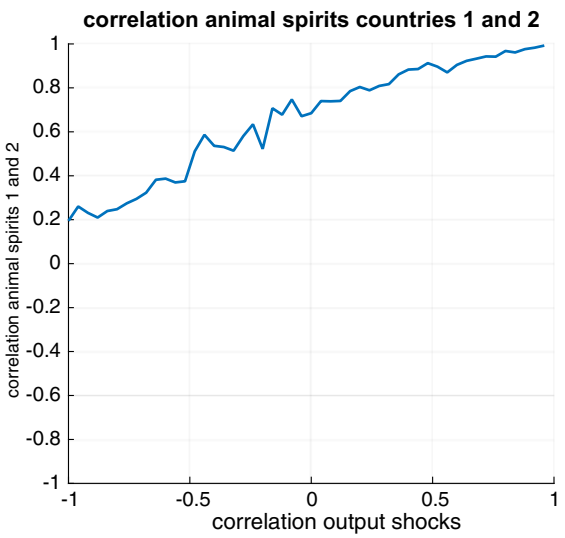

Monetary independence

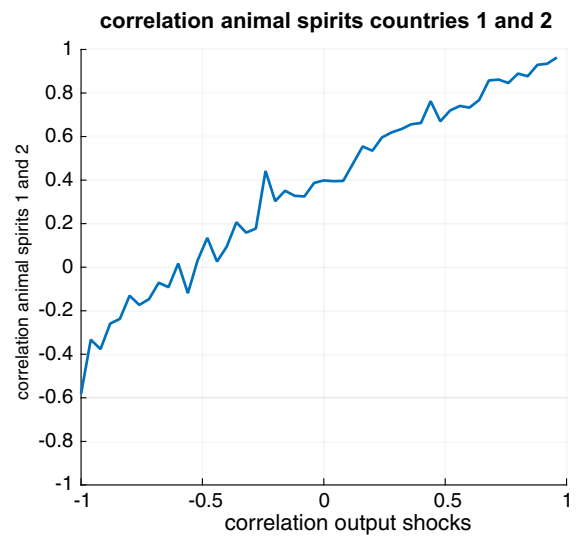

Fig. 13 Correlation animal spirits and correlation shocks

result, with a correlation of shocks equal to 0 the correlation of output gaps reaches 0.7 (see Fig. 12).

This feature is less pronounced in the model of two countries with two central banks (right panels). With correlation of shocks equal to 0 the correlation of output gaps is positive at about 0.4 but lower than in the monetary union. This difference $(0.4$ versus 0.7) has to do with the fact that in this model two central banks set their own interest rate thereby eliminating a source of common shock.

The previous results illustrate an essential feature of our model. This is that even in the absence of correlation of exogenous shocks, the model produces a synchronization of the business cycles endogenously. Put differently, even if shocks are not correlated there is an endogenous mechanism that transforms uncorrelated (and even negatively correlated shocks) into positive correlations of output across countries. The mechanism that produces this was suggested earlier and can be described as follows. Small shocks in output (positive or negative) in one country set in motion a domestic and an international self-reinforcing mechanism. The domestic one comes about through the interaction between changes in the output gap and animal spirits, whereby the positive (negative) output gap creates positive (negative) expectations. The latter then feeds back on the output gap. As a result, there is a two-way causality between the output gap and animal spirits in each country. We illustrate this feature in Table 3. We tested for Granger causality between the simulated output gap (Y1) and animal spirits (ANSPIRITS1) in our model. We

Table 3 Pairwise Granger causality tests

\begin{tabular}{lccc}
\hline Null Hypothesis: & Obs & F-Statistic & Prob. \\
\hline Lags: 1 & & & \\
Y1 does not Granger Cause ANSPIRITS1 & 1998 & 681.507 & 4. E-129 \\
ANSPIRITS1 does not Granger Cause Y1 & & 134.629 & $4 . E-66$ \\
Lags: 2 & & & 162.508 \\
Y1 does not Granger Cause ANSPIRITS1 & 1997 & 50.0886 & $6 . E-22$ \\
ANSPIRITS1 does not Granger Cause Y1 & & & \\
\hline
\end{tabular}


find that we cannot reject the hypothesis that the output gap Granger causes animal spirits and vice versa.

The international self-reinforcing mechanism starts from a shock in one country that is transmitted through trade to the other country, where it sets in motion a selfreinforcing mechanism with animal spirits. This is then transmitted back to the first country. All this leads to the result that an idiosyncratic (uncorrelated) shock in one country leads to correlated output and animal spirits across countries.

\subsection{Synchronization of Business Cycles and Output Stabilization}

The degree of output stabilization exerted by the central bank has important effects on the emergence of animal spirits in our behavioral model. We showed earlier (De Grauwe 2012) that by a more forceful output stabilization (as measured by the coefficient $c_{2}$ in the Taylor rule equation), the central bank can reduce the intensity of the movements in animal spirits. Given the importance of animal spirits in propagating business cycles from one country to the other, the central bank's stabilization efforts can have a significant impact on this propagation. We analyze this issue here.

We do this by studying the sensitivity of the correlations of the output gaps and animal spirits with respect the output coefficient $c_{2}$ in the Taylor rule. We do this for both the monetary union model and the model with two central banks. The results are shown in Figs. 14 and 15. We allow the Taylor output parameter $\left(c_{2}\right)$ to vary from 0 to 2 (horizontal axes) and compute the corresponding correlations of the output gaps (Fig. 14) and animal spirits (Fig. 15).

The results confirm the importance of output stabilization for the international propagation of business cycles. In general when the central bank increases its effort to stabilize output ( $c_{2}$ increases) the correlation of the output gaps across countries declines. Not surprisingly this effect is strongest in the model of monetary independence. The reason is that in this model the existence of two central banks increases their effectiveness in "taming the animal spirits". As a result the international propagation of these animal spirits is also reduced. This leads to less synchronization of the business cycles.
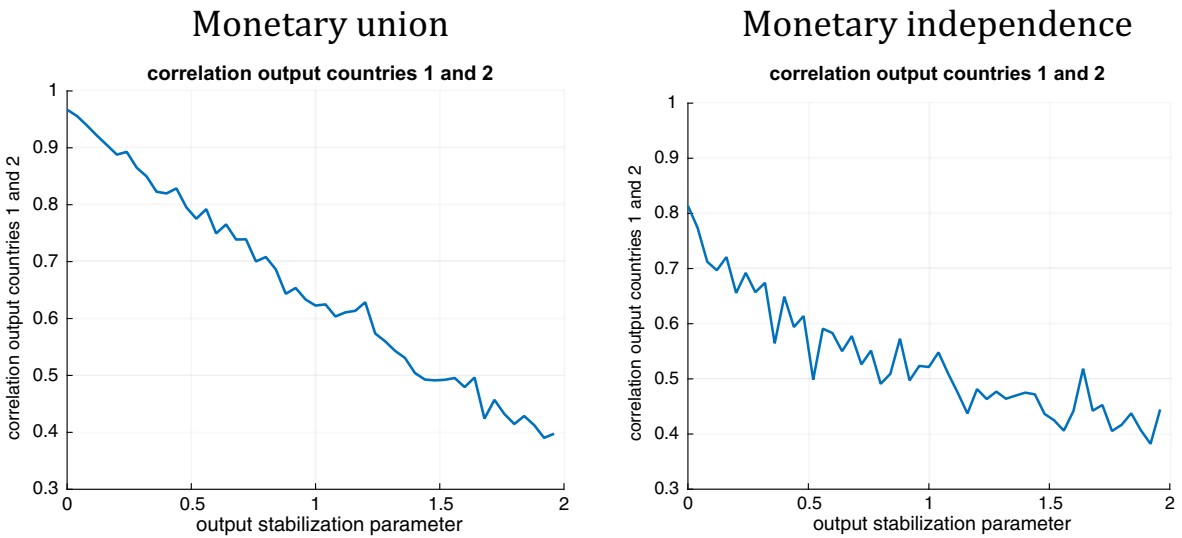

Fig. 14 Synchronization of business cycles and stabilization effort 

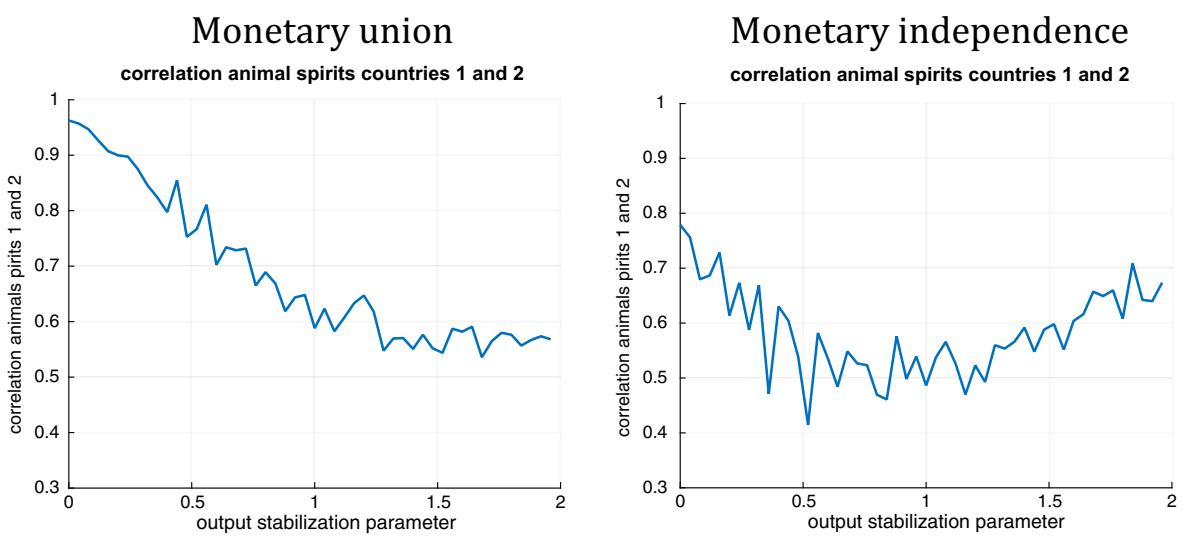

Fig. 15 Synchronization of animal spirits and stabilization effort

\section{Empirical Verification}

Our model has a number of precise predictions that we will subject to empirical testing in this section. We first discuss these theoretical predictions. We then discuss the testing procedure and the results.

\subsection{Theoretical Predictions}

We selected two predictions of our model.

- There is a two-way causality between animal spirits and the output gap, i.e. positive (negative) animal spirits produce a positive (negative) output gap; conversely, a positive (negative) output gap leads to positive (negative) animal spirits. This is in fact a key feature of our theoretical model, which produces a self-reinforcing mechanism that leads to booms and busts, characterized by extreme optimism and pessimism. We have shown this feature in Table 3 where we applied a Granger-causality test on the simulated output gap and animal spirits in country 1 (the results are very similar for country 2 ) and assuming a monetary union.

- Countries that trade with each other experience high correlations of animal spirits. This feature was shown in Fig. 9. We found that when imported consumption exceeds $20 \%$ the correlation of animal spirits between countries reaches 0.9 and more, creating the impression that these countries are subject to the same animal spirits.

\subsection{Empirical Verification}

We now proceed to empirically verifying the two theoretical predictions of our model.

- Do we find a two-way causality between animal spirits and output gap in different countries? In order to answer this question we have to find an empirical counterpart 
of animal spirits. We decided to select business sentiment indicators. These are collected in most countries. The OECD publishes such indicators for most member countries. We will focus on the Eurozone countries here.

We performed Granger causality tests between the business confidence index and the output gap for the Eurozone countries during the period 1995-2015. The results are shown in Table 4. For two countries (Italy and Portugal) the series exhibited a unit root. For these two countries we used the first differences of these variables.

With a few exceptions we find that in most countries we cannot reject the hypothesis of a two-way causality between the output gap and the indicators of business sentiments. This confirms one of the key predictions of our model, i.e. the dynamics of booms and busts is characterized by a process by which waves of optimism and pessimism drive the business cycle, while the latter also influences optimism and pessimism (Table 3).

- Animal spirits play an important role in our model and are at the core of the international transmission of business cycles. We have noted that the latter are highly correlated among industrialized countries. Can we observe a similar degree of correlation of animal spirits as our theoretical model predicts? We used the same business confidence indicators of the previous section and computed the bilateral correlation coefficients during the sample period 1995-2014. We show these bilateral correlation coefficients for the Eurozone and the non-Eurozone OECDcountries in Table 5. We find quite large correlation coefficients as predicted by our model. We also observe that the correlation coefficients in the Eurozone on average are higher than among the other OECD countries, a result that our model also predicts.

\section{Conclusion}

We started this paper by the observation that the degree of synchronization of the business cycles in the industrialized world is very high. It is also higher than what can be explained by trade flows. Mainstream macroeconomic models (Real Business Cycle and DSGE) have found it difficult to replicate the high degree of synchronization in open economy versions of these models. In general they have only be able to do this by assuming sufficiently high correlations of exogenous shocks. Recent attempts to introduce financial flows in these models have been more successful but have also have to rely on assumptions that exogenous financial shocks are correlated, thereby admitting that much of the synchronization of the business cycles finds its origin outside the macroeconomic model.

In this paper we used a two-country behavioral macroeconomic model where the synchronization of the business cycle is produced endogenously. The main channel of synchronization occurs through a propagation of "animal spirits", i.e. waves of optimism and pessimism that get correlated internationally. We found that this propagation occurs with relatively low levels of trade integration. In addition, once a particular level 


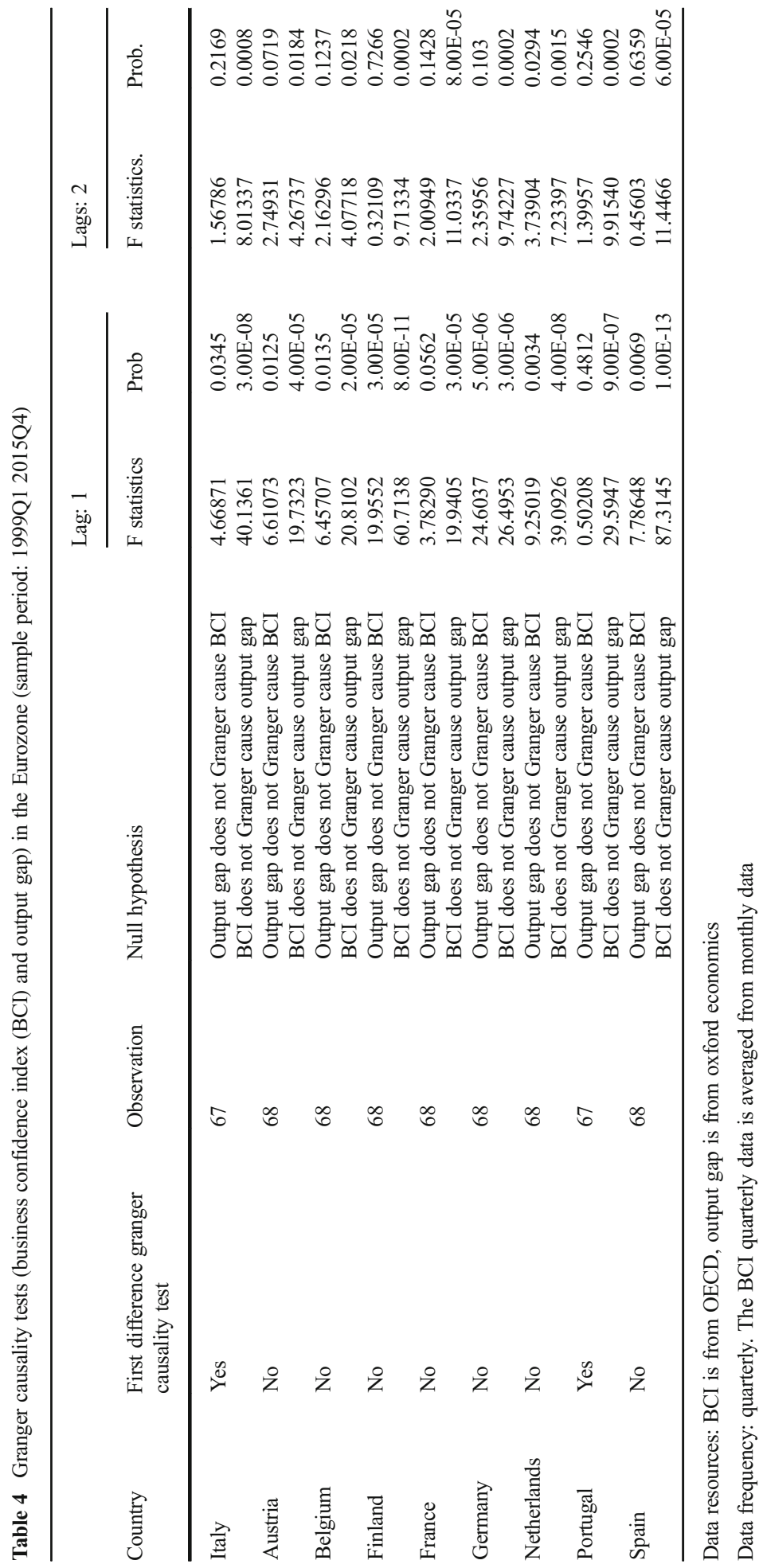


Table 5 Bilateral correlations of business confidence index

\begin{tabular}{|c|c|c|c|c|c|c|c|}
\hline \multicolumn{8}{|c|}{ Eurozone countries } \\
\hline & Austria & Belgium & Finland & France & Germany & Greece & Ireland \\
\hline Austria & 1.0000 & & & & & & \\
\hline Belgium & 0.8551 & 1.0000 & & & & & \\
\hline Finland & 0.8055 & 0.8901 & 1.0000 & & & & \\
\hline France & 0.7211 & 0.8295 & 0.8255 & 1.0000 & & & \\
\hline Germany & 0.8979 & 0.8532 & 0.7610 & 0.7388 & 1.0000 & & \\
\hline Greece & 0.3179 & 0.4565 & 0.5435 & 0.6260 & 0.2159 & 1.0000 & \\
\hline Ireland & 0.3148 & 0.6257 & 0.6031 & 0.6454 & 0.5644 & 0.5207 & 1.0000 \\
\hline Italy & 0.6379 & 0.7740 & 0.8243 & 0.8786 & 0.6635 & 0.7223 & 0.6767 \\
\hline Netherlands & 0.7134 & 0.8397 & 0.8436 & 0.8576 & 0.7803 & 0.6865 & 0.7711 \\
\hline Portugal & 0.5196 & 0.7159 & 0.7551 & 0.8279 & 0.5506 & 0.8056 & 0.6526 \\
\hline \multirow[t]{2}{*}{ Spain } & 0.6172 & 0.7053 & 0.7932 & 0.8529 & 0.5413 & 0.8291 & 0.4719 \\
\hline & Italy & Netherlands & Portugal & Spain & & & \\
\hline Italy & 1.0000 & & & & & & \\
\hline Netherlands & 0.8581 & 1.0000 & & & & & \\
\hline Portugal & 0.8128 & 0.8821 & 1.0000 & & & & \\
\hline Spain & 0.8552 & 0.8022 & 0.8507 & 1.0000 & & & \\
\hline \multicolumn{8}{|c|}{ Stand-alone countries } \\
\hline & Australia & Czech & Denmark & Hungary & Japan & Korea & Norway \\
\hline Australia & 1.0000 & & & & & & \\
\hline Czech & 0.2203 & 1.0000 & & & & & \\
\hline Denmark & 0.1573 & 0.7358 & 1.0000 & & & & \\
\hline Hungary & 0.2829 & 0.6538 & 0.7191 & 1.0000 & & & \\
\hline Japan & 0.1322 & 0.7100 & 0.6118 & 0.4641 & 1.0000 & & \\
\hline Korea & -0.1042 & 0.0319 & 0.2308 & 0.4834 & -0.2284 & 1.0000 & \\
\hline Norway & 0.3020 & 0.7140 & 0.8034 & 0.6670 & 0.7021 & 0.2786 & 1.0000 \\
\hline Poland & 0.1350 & 0.7073 & 0.6189 & 0.6086 & 0.7228 & 0.1642 & 0.6680 \\
\hline Sweden & 0.2898 & 0.6951 & 0.7166 & 0.7535 & 0.4932 & 0.2392 & 0.6114 \\
\hline Switzerland & 0.1264 & 0.7504 & 0.6877 & 0.5777 & 0.6214 & 0.0400 & 0.6219 \\
\hline UK & 0.2556 & 0.6779 & 0.7263 & 0.8065 & 0.6957 & 0.0582 & 0.6545 \\
\hline \multirow[t]{2}{*}{ US } & 0.6672 & 0.3935 & 0.4621 & 0.4681 & 0.4211 & -0.0640 & 0.5495 \\
\hline & Poland & Sweden & Switzerland & UK & US & & \\
\hline Poland & 1.0000 & & & & & & \\
\hline Sweden & 0.6962 & 1.0000 & & & & & \\
\hline Switzerland & 0.6972 & 0.7647 & 1.0000 & & & & \\
\hline UK & 0.6452 & 0.6764 & 0.5609 & 1.0000 & & & \\
\hline US & 0.3535 & 0.5281 & 0.2746 & 0.5276 & 1.0000 & & \\
\hline
\end{tabular}

of trade integration is reached further integration does not increase the synchronization of business cycles anymore.

We also found that the propagation of animal spirits and thus the synchronization of the business cycles is stronger among countries that are members of a monetary union than among "standalone countries" that have their own independent central banks. This difference occurs because in a monetary union the common central bank is a source of common shocks. This helps to introduce correlation between the animal spirits of the member countries.

The degree of output synchronization is very much influenced by the intensity with which the central bank stabilizes output. When that intensity is high, the central bank is able "to tame the animal spirits". In so doing it reduces the propagation dynamics of these animal spirits. 
There are a number of limitations of our analysis. One is that the exchange rate channel in the transmission process was not modeled. This is of no importance for the monetary union model. It matters for the model of two standalone countries with their own central banks. Another one is that in the monetary union model assumes that the import propensity is exogenous and not sensitive to relative price changes. We plan to do research in these two channels in the future.

Acknowledgements The research in this paper was made possible by the European Commission's "Horizon 2020" research fund (Firstrun). It was presented at the CESifo area conference on Money, Macro and International Finance, 26-27 February 2016, and the European Monetary Forum conference at the Bank of England, 15 April, 2016. We are grateful for the comments received from Daniel Gros, Cinzia Alcidi, Patrick Minford, and participants in these seminars.

\section{Appendix 1: Solving the model assuming that $\pi^{*}=0$}

\section{Common central bank}

The solution of the model is found by first substituting (7) into (1) and (4) and rewriting in matrix notation. This yields:

$$
\begin{aligned}
& {\left[\begin{array}{cccc}
1-\frac{0.5 * a 2 * c 2}{1+m} & -\frac{0.5 * a 2 * c 2+m}{1+m} & -\frac{0.5 * a 2 * c 1}{1+m} & -\frac{0.5 * a 2 * c 1}{1+m} \\
-\frac{0.5 * a 2 * c 2+m}{1+m} & 1-\frac{0.5 * a 2 * c 2}{1+m} & -\frac{0.5 * a 2 * c 1}{1+m} & -\frac{0.5 * a 2 * c 1}{1+m} \\
-b 2 & 0 & 1 & 0 \\
0 & -b 2 & 0 & 1
\end{array}\right]\left[\begin{array}{c}
y_{t}^{1} \\
y_{t}^{2} \\
\pi_{t}^{1} \\
\pi_{t}^{2}
\end{array}\right]=\left[\begin{array}{cccc}
\frac{a_{1}}{1+m} & 0 & \frac{-a_{2}}{1+m} & 0 \\
0 & \frac{a_{1}}{1+m} & 0 & \frac{-a_{2}}{1+m} \\
0 & 0 & b 1 & 0 \\
0 & 0 & 0 & b 1
\end{array}\right]} \\
& {\left[\begin{array}{c}
\tilde{E}_{t} y_{t}^{1} \\
\tilde{E}_{t} y_{t}^{2} \\
\tilde{E}_{t} \pi_{t}^{1} \\
\tilde{E}_{t} \pi_{t}^{2}
\end{array}\right]+\left[\begin{array}{cccc}
\frac{1-a_{1}}{1+m} & 0 & 0 & 0 \\
0 & \frac{1-a_{1}}{1+m} & 0 & 0 \\
0 & 0 & 1-b_{1} & 0 \\
0 & 0 & 0 & 1-b_{1}
\end{array}\right]\left[\begin{array}{c}
y_{t-1}^{1} \\
y_{t-1}^{2} \\
\pi_{t-1}^{1} \\
\pi_{t-1}^{2}
\end{array}\right]+\left[\begin{array}{c}
a 2 * c 3 \\
a 2 * c 3 \\
0 \\
0
\end{array}\right] r_{t-1}+\left[\begin{array}{c}
\frac{a 2 * u_{t}}{1+m}+\frac{\varepsilon_{t}^{1}}{1+m} \\
\frac{a 2 * u_{t}}{1+m}+\frac{\varepsilon_{t}^{2}}{1+m} \\
\eta_{t}^{1} \\
\eta_{t}^{2}
\end{array}\right]}
\end{aligned}
$$

Or

$$
A Z_{t}=\boldsymbol{B} \widetilde{E_{t}} Z_{t+1}+C Z_{t-1}+b r_{t-1}+v_{t}
$$

where bold characters refer to matrices and vectors. The solution for $\boldsymbol{Z}_{\boldsymbol{t}}$ is given by

$$
Z_{t}=A^{-1}\left[\boldsymbol{B} \widetilde{E_{t}} Z_{t+1}+C Z_{t-1}+b r_{t-1}+v_{t}\right]
$$

The solution exists if the matrix $\boldsymbol{A}$ is non-singular. The system (31) describes the solution for $y_{t}^{1}, y_{t}^{2}, \pi_{t}^{1}$ and $\pi_{t}^{2}$ given the forecasts of $y_{t}^{1}, y_{t}^{2}, \pi_{t}^{1}$ and $\pi_{t}^{2}$. The latter have been specified in Eqs. (16) to (27) and can be substituted into (A2). We then obtain a system 
of non-linear difference equations. Finally, the solution for $r_{t}$ is found by substituting $y_{t}$ and $\pi_{t}$ obtained from (31) into (7).

The model has non-linear features making it difficult to arrive at analytical solutions. That is why we will use numerical methods to analyze its dynamics. In order to do so, we have to calibrate the model, i.e. to select numerical values for the parameters of the model. In appendix 2 the parameters used in the calibration exercise are presented. They are based on Gali (2008). The model was calibrated in such a way that the time units can be considered to be quarters. A sensitivity analysis of the main results to changes in the some of the parameters of the model will be presented. The three shocks (demand shocks, supply shocks and interest rate shocks) are independently and identically distributed (i.i.d.) with standard deviations of $0.5 \%$. We allow the demand and supply shocks to be correlated across countries. It will turn out that these correlations affect the transmission of business cycles across countries.

\section{Two country model with 2 central banks}

Similar to the solutions to the model of a common central bank, we have the following for a two country model with 2 central banks.

$$
\begin{aligned}
& {\left[\begin{array}{cccc}
1-\frac{a 2 * c 2}{1+m} & -\frac{m}{1+m} & -\frac{a 2 * c 1}{1+m} & 0 \\
-\frac{m}{1+m} & 1-\frac{a 2 * c 2}{1+m} & 0 & -\frac{a 2 * c 1}{1+m} \\
-b 2 & 0 & 1 & 0 \\
0 & -b 2 & 0 & 1
\end{array}\right]\left[\begin{array}{c}
y_{t}^{1} \\
y_{t}^{2} \\
\pi_{t}^{1} \\
\pi_{t}^{2}
\end{array}\right]} \\
& =\left[\begin{array}{cccc}
\frac{a 1}{1+m} & 0 & \frac{-a 2}{1+m} & 0 \\
0 & \frac{a 1}{1+m} & 0 & \frac{-a 2}{1+m} \\
0 & 0 & b 1 & 0 \\
0 & 0 & 0 & b 1
\end{array}\right]\left[\begin{array}{c}
\widetilde{E}_{t} y_{t}^{1} \\
\widetilde{E}_{t} y_{t}^{2} \\
\widetilde{E}_{t} \pi_{t}^{2} \\
\widetilde{E}_{t} \pi_{t}^{2}
\end{array}\right]+\left[\begin{array}{cccc}
\frac{1-a_{1}}{1+m} & 0 & 0 & 0 \\
0 & \frac{1-a_{1}}{1+m} & 0 & 0 \\
0 & 0 & 1-b 1 & 0 \\
0 & 0 & 0 & 1-b 1
\end{array}\right]\left[\begin{array}{c}
y_{t-1}^{1} \\
y_{t-1}^{2} \\
\pi_{t-1}^{1} \\
\pi_{t-1}^{2}
\end{array}\right] \\
& +\left[\begin{array}{c}
\frac{a 2 * c 3}{1+m} \\
0 \\
0 \\
0
\end{array}\right] r_{t-1}^{1}+\left[\begin{array}{c}
a 2 * u_{t} \\
\frac{a 2 * c 3}{1+m}+\frac{\varepsilon_{t}^{2}}{1+m} \\
0 \\
0
\end{array}\right] r_{t-1}^{2}+\left[\begin{array}{c}
\frac{a 2 * u_{t}}{1+m}+\frac{\varepsilon_{t}^{2}}{1+m} \\
\eta_{t}^{1+m} \\
\eta_{t}^{2}
\end{array}\right]
\end{aligned}
$$

Or

$$
\boldsymbol{A} \boldsymbol{Z}_{\boldsymbol{t}}=\boldsymbol{B} \widetilde{\boldsymbol{E}_{\boldsymbol{t}}} \boldsymbol{Z}_{\boldsymbol{t}+1}+\boldsymbol{C} \boldsymbol{Z}_{\boldsymbol{t}-1}+\boldsymbol{b} 1 r_{t-1}^{1}+\boldsymbol{b} 2 r_{t-1}^{2}+\boldsymbol{v}_{\boldsymbol{t}}
$$

where bold characters refer to matrices and vectors. The solution for $\boldsymbol{Z}_{\boldsymbol{t}}$ is given by

$$
Z_{t}=A^{-1}\left[B \widetilde{E_{t}} Z_{t+1}+C Z_{t-1}+b 1 r_{t-1}^{1}+b 2 r_{t-1}^{2}+v_{t}\right]
$$

The solution is obtained by substituting the forecasts of output gap and inflation obtained from (14)-(27). 


\section{Appendix 2}

Table 6 Standard parameter values of the calibrated model

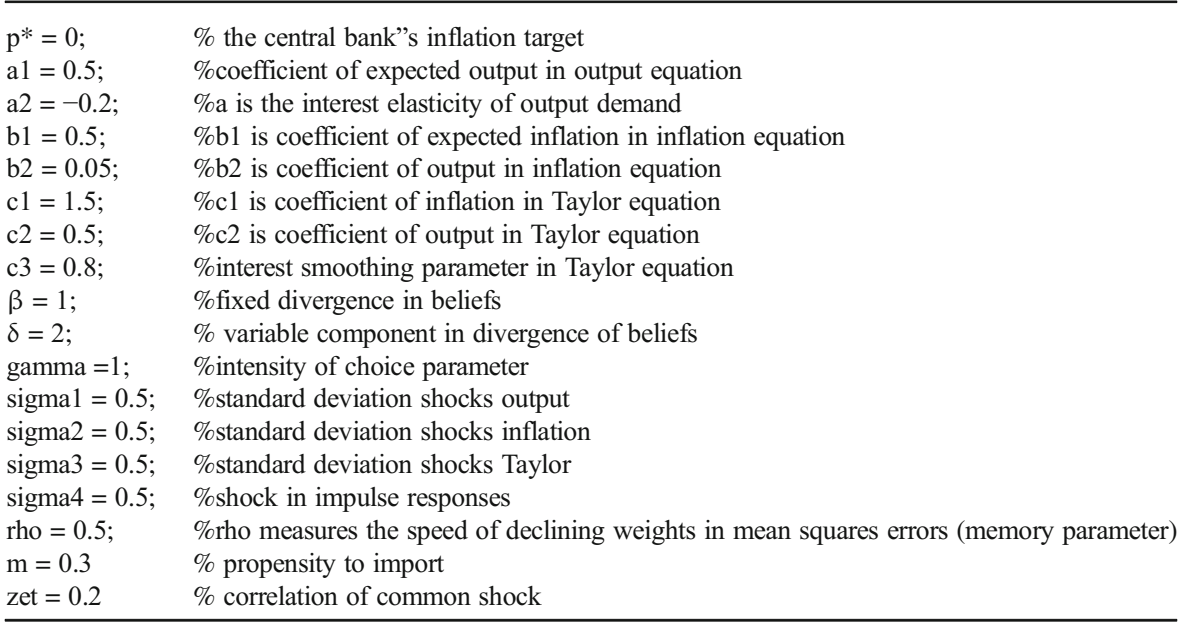

Open Access This article is distributed under the terms of the Creative Commons Attribution 4.0 International License (http://creativecommons.org/licenses/by/4.0/), which permits unrestricted use, distribution, and reproduction in any medium, provided you give appropriate credit to the original author(s) and the source, provide a link to the Creative Commons license, and indicate if changes were made.

\section{References}

Akerlof G, Shiller R (2009) Animal spirits. How human psychology drives the economy and why it matters for global capitalism. Princeton University Press. 230 pp

Alpanda S, Aysun U (2014) International transmission of financial shocks in an estimated DSGE model. J Int Money Financ 47:21-55

Anderson S, de Palma A, Thisse J-F (1992) Discrete choice theory of product differentiation. MIT Press, Cambridge

Artis M, Cleays P (2005) What holds cycles together? European University Institute, Discussion Paper

Backus D, Kehoe P, Kydland F (1992) International real business cycles. J Polit Econ 100(4):745-775

Belke A, Domnick C, Gros D (2016) Business Cycle Synchronization in the EMU: Core vs. Periphery, CEPS Working Document, no. 427, Brussels

Blattner T, Margaritov (2010) Towards a Robust Policy Rule for the Euro Area, ECB Working Paper Series, no. 1210 , June

Bordo, Helbling (2004) Have National business cycles become more synchronized? NBER Working Paper No. 10130, December 2003

Branch W, Evans G (2006) Intrinsic heterogeneity in expectation formation. J Econ Theory 127:264-295

Brazier A, Harrison R, King M, Yates T (2006) The danger of inflation expectations on macroeconomic stability: heuristic switching in an overlapping generations monetary model. International Journal of Central Banking 32:2428-2452

Brock W, Hommes C (1997) A rational route to randomness. Econometrica 65:1059-1095

Calvo G (1983) Staggered prices in a utility maximizing framework. J Monet Econ 12:383-398 
Camerer C, Loewenstein G, Prelec D (2005) Neuroeconomics: how neuroscience can inform economics. J Econ Lit 43:9-64

Canova F, Dellas H (1993) Trade interdependence and the international business cycle. J Int Econ 34:23-47

Cass D, Shell K (1983) Do Sunspots Matter? J Polit Econ 91(21):193-228

Colander D, Howitt P, Kirman A, Leijonhufvud A, Mehrling P (2008) Beyond DSGE models: toward an empirically based macroeconomics. Am Econ Rev 98(2):236-240

Damasio A (2003) Looking for Spinoza. Joy, Sorrow and the feeling brain. Harvest, pp 368

De Grauwe P (2012) Lectures on behavioral macroeconomics. Princeton University Press

De Grauwe P, Grimaldi M (2006) The exchange rate in behavioral finance framework. Princeton University Press, Princeton ISBN 9780691121635

De Grauwe P, Ji Y (2016) Flexibility versus stability. A difficult trade-off in the Eurozone. London, Centre for Economic Policy Research. http://www.cepr.org/active/publications/discussion_papers/dp.php?dpno=11372

De Haan J, Inklaar R, Jong-A-Pin R (2008) Will business cycles in the euro area converge? A critical survey of empirical research. J Econ Surv 22(2):234-273

Devereux MB, Yetman J (2010) Leverage constraints and the international transmission of shocks. J Money Credit Bank 42:71-105

Farmer REA (2006) Animal Spirits, Palgrave Dictionary of Economics

Farmer JD, Foley D (2009) The economy needs agent-based modelling. Nature 460(7256):685-686

Frankel JA, Rose A (1998) The endogeneity of the optimum currency area criteria. Econ J 108(July):10091025

Galí J (2008) Monetary policy, inflation and the business cycle. Princeton University Press. 203 pp

Gatti D, Desiderio S, Gaffeo E, Cirillo P, Gallegati M (2011) Macroeconomics from the bottom-up (Vol. 1). Springer Science \& Business Media

Gertler M, Gilchrist S, Natalucci FM (2007) External constraints on monetary policy and the financial accelerator. J Money Credit Bank 39:295-330

Giannone D, Lenza M, Reichlin L (2008) Business cycles in the Euro area, NBER Working Paper, no. 14529, Cambridge, Mass

Gigerenzer G, Selten R (2002) Bounded rationality. MIT Press, Cambridge ISBN 0-262-57164-1

Gigerenzer G, Todd PM (1999) Simple heuristics that make us smart. Oxford University Press, New York

Hommes C (2016) Behavioral Macroeconomics with Heterogeneous Expectations and Interacting Agents, Discussion Paper, CenDEF, University of Amsterdam

Hommes C, Lustenhouwer J (2016) Managing heterogeneous and unanchored expectations: a monetary policy analysis, Working Paper, Tinbergen Institute, Rotterdam

Kahneman D (2002) Maps of Bounded Rationality: A Perspective on Intuitive Judgment and Choice, Nobel Prize Lecture, December 8, Stockholm (also published in American Economic Review, 2003)

Keynes, John Maynard (1936) The general theory of employment, interest and money. Macmillan, London (reprinted 2007)

Kirman A, (1993), Ants, rationality and recruitment. Q J Econ 108:137-156

Kollmann R (1995) Consumption, real exchange rates, and the structure of international asset markets. J Int Money Financ 14:191-211

Kollmann R (2012) Global Banks, Financial Shocks and International Business Cycles: Evidence from an Estimated Model. Centre for Economic Policy Research. Discussion Paper No. 8985

Pfajfar D, Žakelj B (2009) Experimental evidence on inflation expectation formation. Tilburg University

Rey H (2014) International Channels of Transmission of Monetary Policy and the Mundellian Trilemma, Mundell Fleming Lecture, International Monetary Fund, Washington D.C., November

Simon H (1957) A behavioral model of rational choice. In: Models of man, social and rational: mathematical essays on rational human behavior in a social setting. Wiley, New York

Sonnenschein H (1972) Market excess-demand functions. Econometrica 40(3):549-563

Stockman A, Tesar L (1995) Tastes and Technology in a Two-Country Model of the business cycle: explaining international Comovements. Am Econ Rev 85(1):168-185

Taylor, John B (1993) Discretion versus policy rules in practice. Carn-Roch Conf Ser Public Policy 39:195-214

Tesfatsion L (2001) Guest editor, special issue on agent-based computational economics. J Econ Dyn Control $25: 3-4$

Tesfatsion and Judd KL (eds) (2006) Handbook of computational economics, Volume 2. Elsevier, p 829-1660

Westerhoff F (2012) Interactions between the real economy and the stock market: A simple agent based approach, Discrete Dybamics in Nature and Society, vol. 2012

Woodford M (2003) Interest and prices: foundations of a theory of monetary policy. Princeton University Press 